Supporting Information

\title{
Biodegradable Anti-ultraviolet Film from Modified Gallic Acid Crosslinked Gelatin
}

Authors: Linxin Guo ${ }^{\mathrm{a} b}$, Taotao Qiang ${ }^{\mathrm{a}} *$, Yangmin $\mathrm{Ma}^{\mathrm{c}} *$, Longfang Ren ${ }^{\mathrm{a}}$, Chao Zhu ${ }^{\mathrm{d}}$ Affiliations:

a College of Bioresources Chemical and Materials Engineering, Shaanxi University of Science and Technology, Xuefu Road, Weiyang district, Xi'an 710021, Shaanxi province, China.

${ }^{b}$ College of Chemistry and Chemical Engineering, Ankang University, Yucai Road, Hanbin district, Ankang 725000, Shaanxi province, China.

${ }^{c}$ Key Laboratory of Chemical Additives for China National Light Industry, Xuefu Road, Weiyang district, Xi'an 710021, Shaanxi province, China.

${ }^{d}$ College of Environmental Science and Engineering, Shaanxi University of Science and Technology, Xuefu Road, Weiyang district, Xi'an 710021, Shaanxi province, China.

*Corresponding author:

Taotao Qiang. E-mail address: qiangtt515@163.com

Yangmin Ma. E-mail address: mym63@sina.com Authors:

Linxin Guo. E-mail address: glx9933@foxmail.com

Longfang Ren. E-mail address: renlongfang@ sust.edu.cn

Chao Zhu. E-mail address: 304545693@qq.com

Number of pages: 31

Number of figures: 29 


\section{Content}

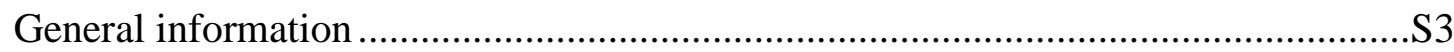

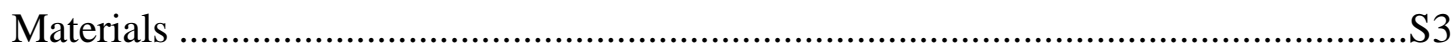

Influence of different acid solvents on the yield of modification reaction .................S3

Influence of solvent dosage on the yield of modification reaction ............................S4

Influence of HMTA dosage on the yield of modification reaction.............................S5

Influence of temperature on the yield of modification reaction ................................S6

Influence of time on the yield of modification reaction ............................................

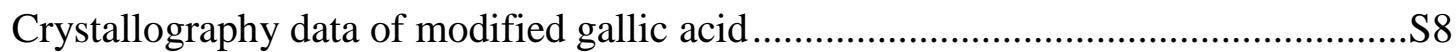

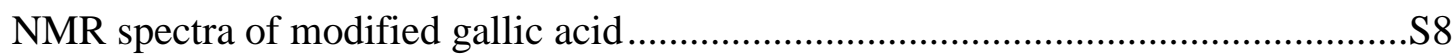

Crosslinking degree of different DFGA concentration ..............................................

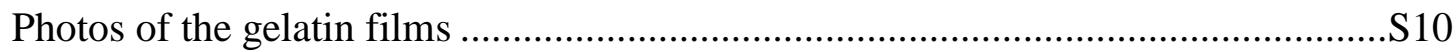

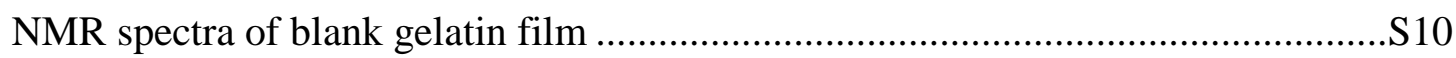

NMR spectra of gallic acid composite gelatin film .............................................S11

NMR spectra of modified gallic acid crosslinked gelatin film ...............................S11

Crosslinking mechanism model by modified gallic acid and glycine .....................S12

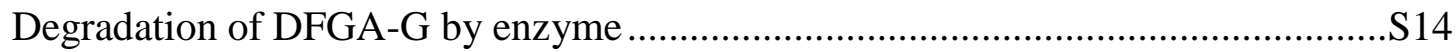

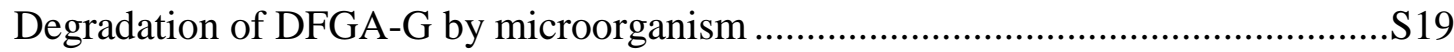

Degradation of DFGA-G by activated sludge composting ..................................S23

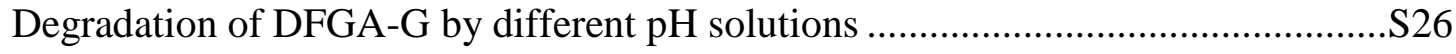

The microscopic morphology of different gelatin films after swelled in water ........S28

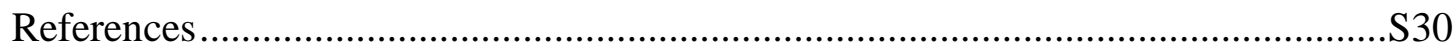




\section{General information}

The reactions involved in this study were carried out under a mild condition, with stirring under air atmosphere and the temperature of bath around vessel. Thin-layer chromatography (TLC) was analyzed using GF-254 silica gel plate and observed under UV light (254 nm). Column chromatography silica gel (200-300 mesh) was purchased from Qingdao Ocean Chemical (China). NMR spectra were measured by Bruker Advance NEO $600 \mathrm{MHz}$ or Bruker Advance III $400 \mathrm{MHz}$, and referenced with deuterated solvents (DMSO $\delta$ : $\mathrm{H} 7.26$ ppm, C 39.52 ppm; $\mathrm{D}_{2} \mathrm{O} \delta: \mathrm{H} 4.79$ ppm).

\section{Materials}

Formic acid, acetic acid, propionic acid, trifluoroacetic acid, polyphosphoric acid, glycine and gallic acid were purchased from Shanghai Maclean Biochemical Technology Co. Ltd., China. Hexamethylenetetramine (HMTA) was prepared from Chengdu Kelong Chemical Co. Ltd., China. Deuterated DMSO and $\mathrm{D}_{2} \mathrm{O}$ were provided by Ningbo Triking Chemical Technology Co. Ltd., China. Acid protease (Enzyme activity is 2000 u.g $^{-1}$, pH 5-8) was provided by Sichuan Dawei Technology Co. Ltd., China. Microbial degradation test was conducted with Saccharomyces cerevisiae. The experimental activated sludge was surplus sludge from a municipal wastewater treatment plant. Polylactic acid film was prepared with commercial polylactic acid particles. All reagents used were analytical grade and used without further purification.

\section{Influence of different acid solvents on the yield of modification reaction}

Basically, $1 \mathrm{mmol}(184.1 \mathrm{mg}$ ) of methyl gallate were added into $15 \mathrm{mmol}$ of acid solvents (formic acid, acetic acid, propionic acid, trifluoroacetic acid and polyphosphoric acid), stirring was kept to get a fully dissolving. Then $1.5 \mathrm{mmol}$ HMTA was slowly added into the above solution and kept stirring at $90{ }^{\circ} \mathrm{C}$ for $60 \mathrm{~min}$. After the reaction was completed, $10 \mathrm{~mL}$ of distilled water was added, and the mixture was stirred for $20 \mathrm{~min}$ to cool. The mixture was distilled under reduced pressure to remove the solvent. Silica gel column chromatography was used for separating to gain the light yellow solid, in which petroleum ether and ethyl acetate 
(1:1) were using as eluents. The separation yields of different solvent are shown in Figure S1. It can be seen from the figure that different acid solvents can react under the given conditions. Specifically, the reaction yields of polyphosphoric acid (13\%), formic acid (9\%), acetic acid (7\%), and propionic acid (5\%) decreased sequentially, while trifluoroacetic acid (TFA) exhibited the maximum reaction yield of 34\%, which shows a significant increasing compared with all other samples. According to the Duff reaction mechanism, the enhanced performance of TFA could be assigned to the strong dissociated effect of protons owing to its strong acidity, which is beneficial to the formation of reaction intermediates and thus improves the reaction yield. Therefore, TFA was chosen as the solvent for the Duff modification reaction of methyl gallate.

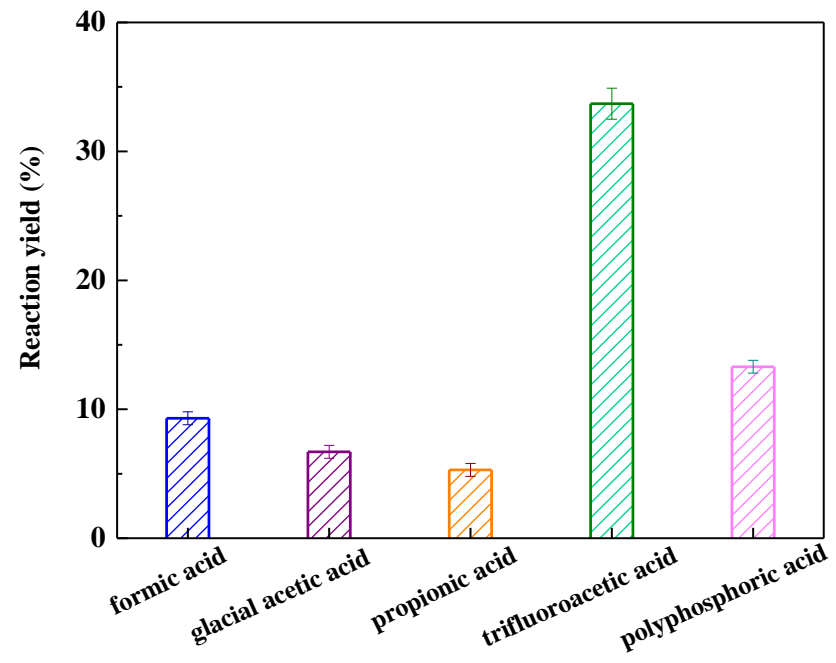

Figure S1. Influence of different acid solvents on the yield of modification reaction.

\section{Influence of solvent dosage on the yield of modification reaction}

One mmol (184.1 mg) of methyl gallate were added into TFA $(5,10,15,20,25$, $30 \mathrm{mmol}$ ) solvent and kept stirring to fully dissolve. Then 1.5 mmol HMTA was slowly added into the above solution with stirring at $90{ }^{\circ} \mathrm{C}$ for $60 \mathrm{~min}$. After the reaction was completed, $10 \mathrm{~mL}$ of distilled water was added, and the mixture was stirred for $20 \mathrm{~min}$ to cool. The mixture was distilled under reduced pressure to remove the solvent. The separation was carried out by silica gel column chromatography, using petroleum ether and ethyl acetate (1:1) as eluents to obtain a light yellow solid, and the separation yield was calculated. The separation yield was then calculated as 
shown in Figure S2. It can be seen from the figure that when the solvent dosage was 5 mmol (25\%), TFA was not enough to dissolve the raw materials and HMTA in the reaction process, resulting in a low reaction yield. When the amount of TFA increased to $10 \mathrm{mmol}(34 \%)$, the yield of the modification reaction increased significantly. However, the yield has no obvious change when the amount of reaction solvent continued to increase. Therefore, the optimal amount of TFA for the modification reaction is $10 \mathrm{mmol}$. It could be noticed that when TFA is used as a reaction solvent, on the one hand, the sufficient amount is vital to dissolve the raw materials in the reaction system; on the other hand, it can provide protons for the modification reactions and promote the formation of reaction intermediates as a protic acid.

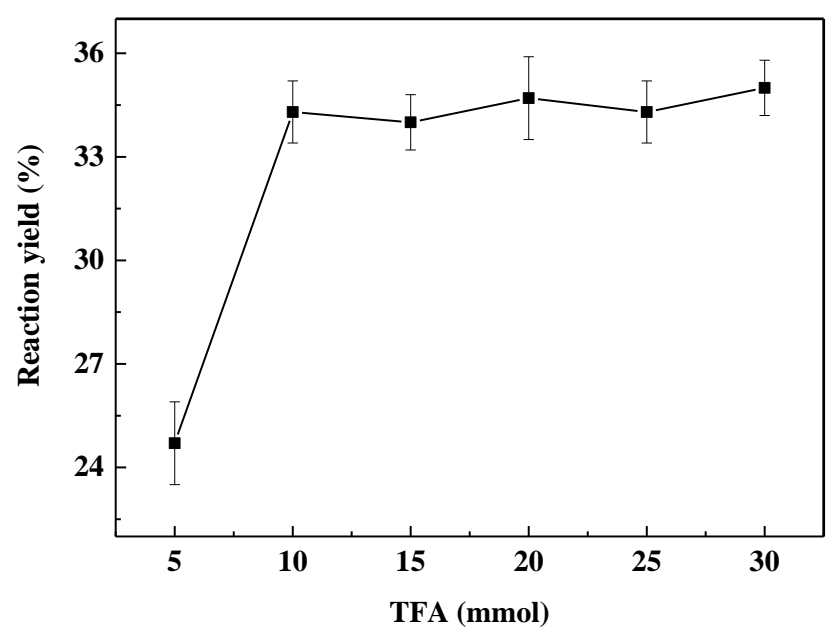

Figure S2. The effect of solvent dosage on reaction yield.

\section{Influence of HMTA dosage on the yield of modification reaction}

Added $1 \mathrm{mmol}(184.1 \mathrm{mg})$ of methyl gallate into $10 \mathrm{mmol}$ of TFA, and kept stirring to dissolve it. Then a certain amount of $\operatorname{HMTA}(0.5,1.0,1.5,2.0,2.5,3.0$ mmol) was slowly added with stirring at $90{ }^{\circ} \mathrm{C}$ for $60 \mathrm{~min}$. After the reaction was completed, $10 \mathrm{~mL}$ of distilled water was added, and the mixture was stirred for $20 \mathrm{~min}$ to cool. For solvent removing, distilled the above solution under reduced pressure. The separation was carried out by silica gel column chromatography, using petroleum ether and ethyl acetate (1:1) as eluents to obtain a light yellow solid, and the separation yield was calculated with the result shown in Figure S3. It can be noticed that the HMTA dosage has a significant effect on the yield of the modification 
reaction. The modified yield increased significantly with the increase in the amount of HMTA ranging from $0.5 \mathrm{mmol}(16 \%)$ to $2.0 \mathrm{mmol}(38 \%)$. As one of the key raw materials for Duff reaction, HMTA can form a benzyl intermediate with methyl gallate by breaking its own chemical bond. The reaction yield no longer increased significantly when the dosage of HMTA kept increasing. Therefore, the optimal dosage of HMTA is $2.0 \mathrm{mmol}$.

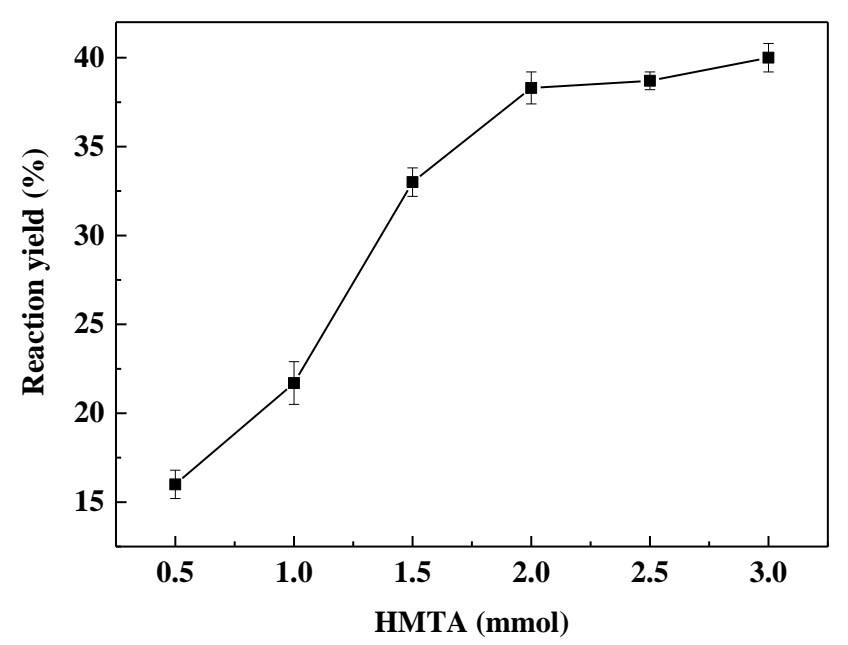

Figure S3. The effect of HMTA dosage on reaction yield.

\section{Influence of temperature on the yield of modification reaction}

Added $1 \mathrm{mmol}(184.1 \mathrm{mg})$ of methyl gallate into $10 \mathrm{mmol}$ of TFA, and kept stirring to dissolve it. Then slowly added 2.0 mmol HMTA into the above solution with stirring for $60 \mathrm{~min}$ at the set temperature $\left(70,80,90,100,110,120^{\circ} \mathrm{C}\right)$. After the reaction was completed, $10 \mathrm{~mL}$ of distilled water was added, and the mixture was stirred for $20 \mathrm{~min}$ to cool. The mixture was distilled under reduced pressure to remove the solvent. Separation was carried out by silica gel column chromatography using petroleum ether and ethyl acetate (1:1) as the eluent. The separation yields at different reaction temperatures were shown in Figure S4. It can be seen from the figure that the reaction yield increases with the increase of temperature in the range of $70{ }^{\circ} \mathrm{C}(20 \%)$ to $90{ }^{\circ} \mathrm{C}(39 \%)$. This could be assigned to the higher temperature will faster the movement of substrate molecules, thus increase the probability of molecular collisions between methyl gallate and HMTA, further results in a more efficient reaction. Notably, when the reaction temperature raised to $120^{\circ} \mathrm{C}(35 \%)$, the reaction 
yield demonstrated a decreased trend, which was due to the molecular structure of the substrate could be destroyed when the temperature was too high. Therefore, the optimal modification reaction temperature is $90^{\circ} \mathrm{C}$.

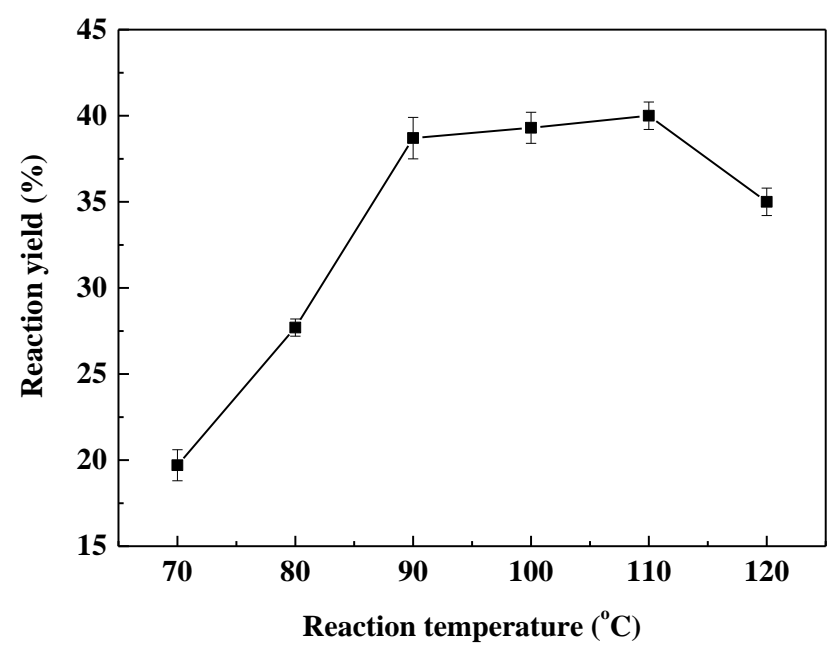

Figure S4. The effect of reaction temperature on yield.

\section{Influence of time on the yield of modification reaction}

Took $1 \mathrm{mmol}(184.1 \mathrm{mg})$ of methyl gallate, and stirring dissolved it into 10 mmol of TFA. Then slowly added 2.0 mmol of HMTA into the above solution with, stirring for a certain period of time $(20,40,60,80,100,120 \mathrm{~min})$ at $90{ }^{\circ} \mathrm{C}$. After the reaction was completed, $10 \mathrm{~mL}$ of distilled water was added, and the mixture was stirred for $20 \mathrm{~min}$ to cool. The mixture was distilled under reduced pressure to remove the solvent. The separation was carried out by silica gel column chromatography, using petroleum ether and ethyl acetate (1:1) as eluents to obtain a light yellow solid, and the separation yield was calculated as shown in Figure S5. It can be seen that the reaction yield increased with the increasing of reaction time. After the reaction proceeded to $80 \mathrm{~min}(47 \%)$, the yield became stabilized and tend to display a downward trend after 120 min (46\%). Therefore, the optimal modification reaction time is $80 \mathrm{~min}$. 


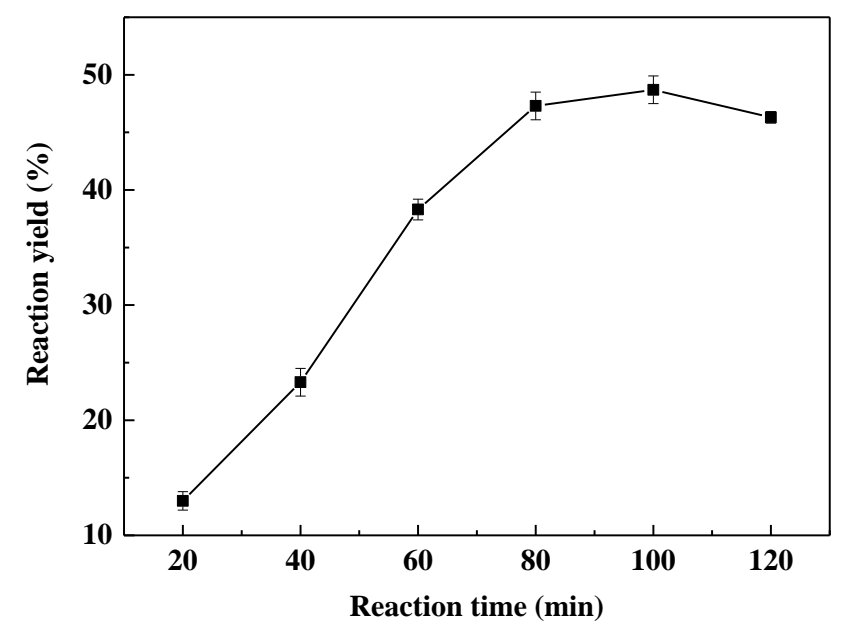

Figure S5. The effect of reaction time on yield.

\section{Crystallography data of modified gallic acid}

Using Bruker D8 QUEST diffractometer, the crystal structure of Methyl 2-formyl-3,4,5-trihydroxybenzoate was determined at room temperature. CCDC 2025854 contains the supplementary crystallographic data for this paper. These data can be obtained free of charge via www.ccdc.cam.ac.uk/data_request/cif, or by emailing data_request@ccdc.cam.ac.uk.<smiles>COC(=O)c1cc(O)c(O)c(O)c1C=O</smiles>
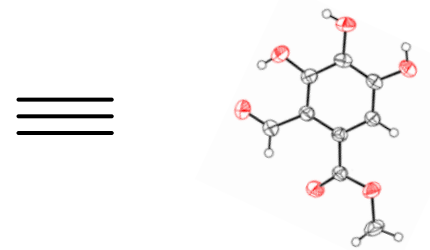

Figure S6. Molecular structure methyl 2-formyl-3,4,5-trihydroxybenzoatede.

\section{NMR spectra of modified gallic acid}




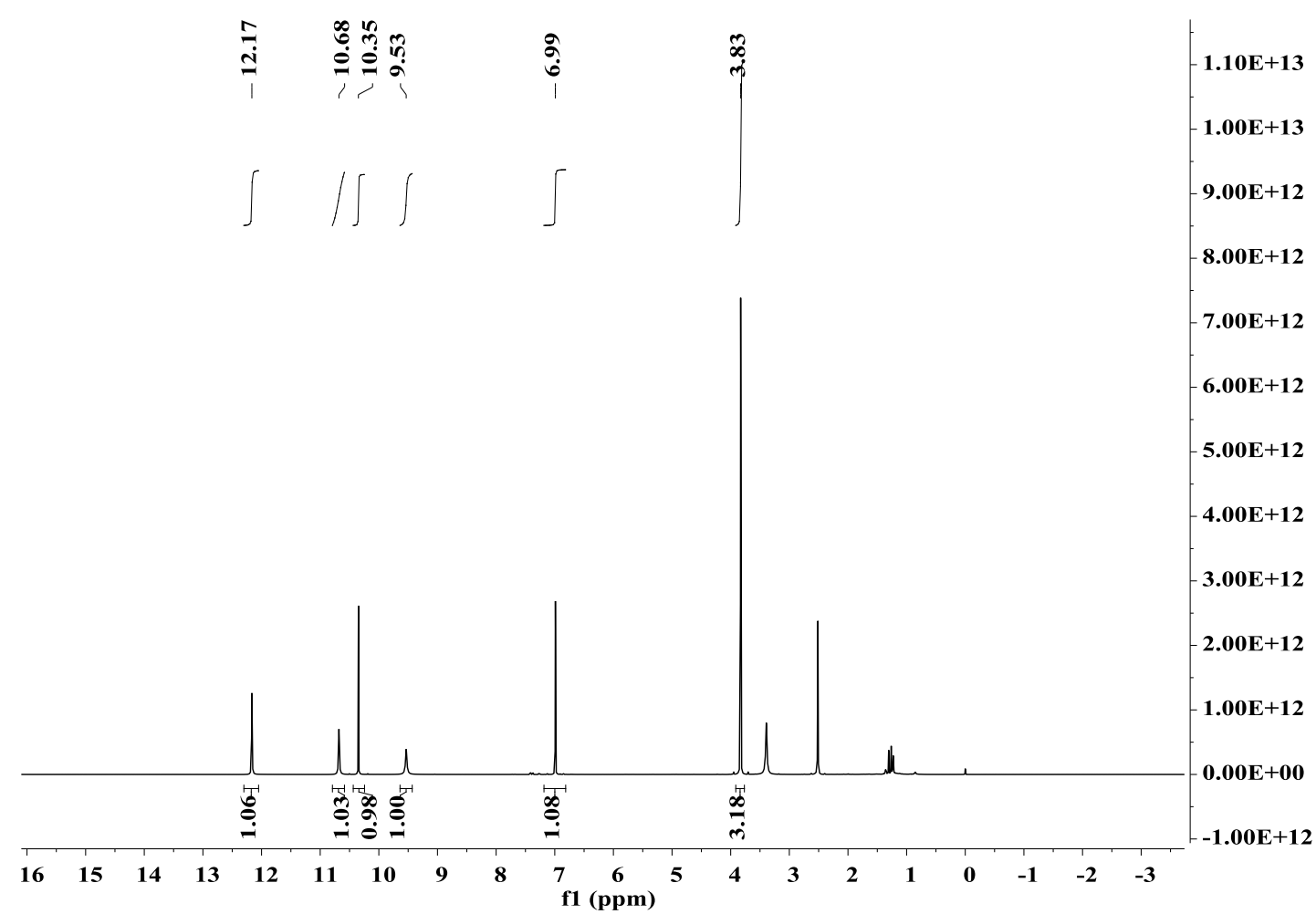

Figure S7. ${ }^{1} \mathrm{H}$ NMR spectra of modified gallic acid.

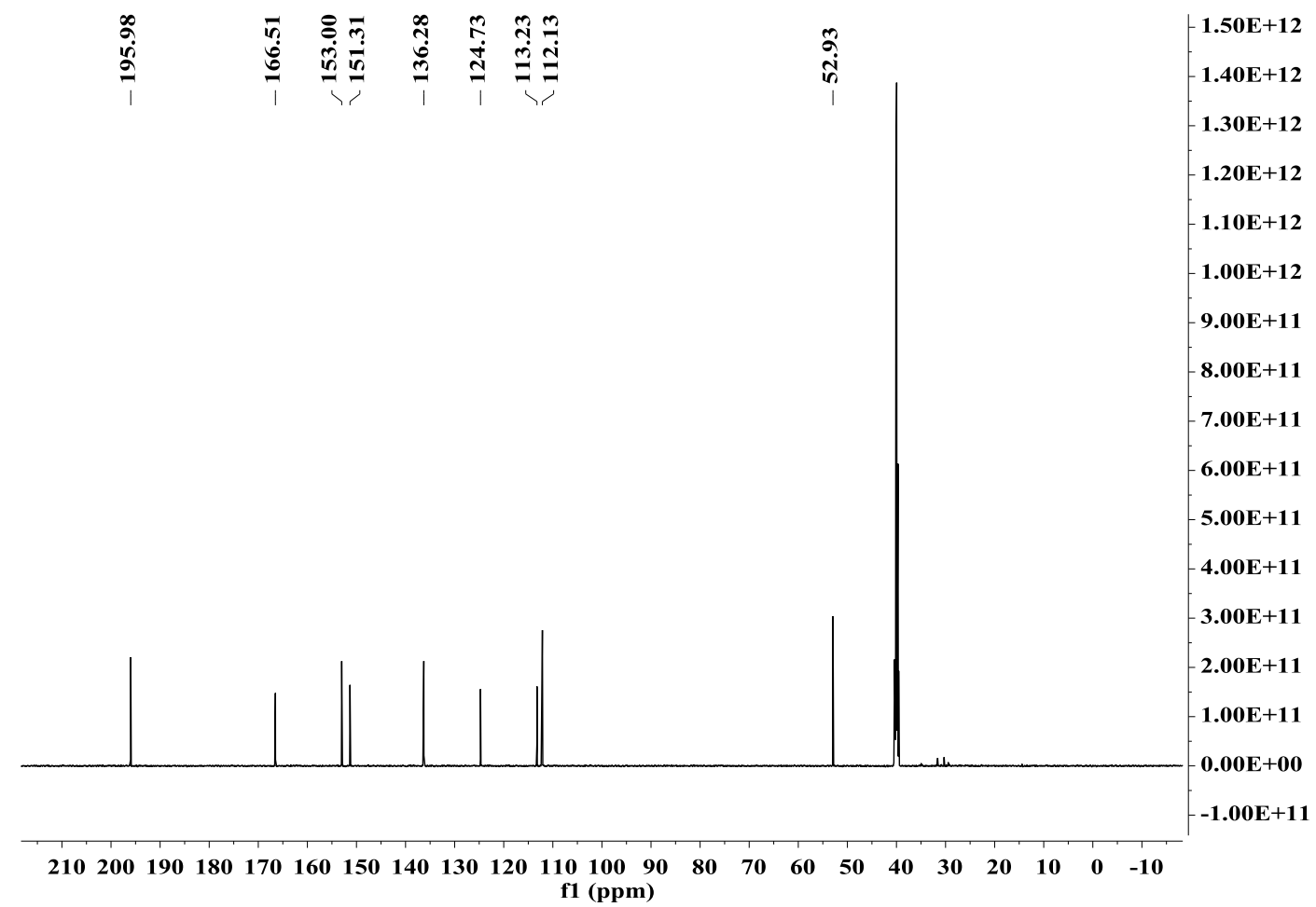

Figure S8. ${ }^{13} \mathrm{C}$ NMR spectra of modified gallic acid.

\section{Crosslinking degree of different DFGA concentration}




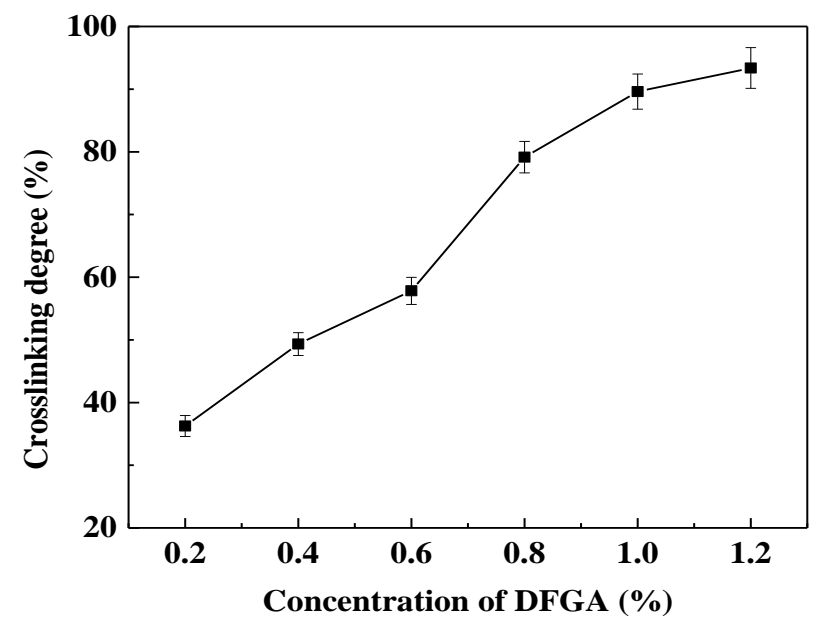

Figure S9. Crosslinking degree of different DFGA concentration

Photos of the gelatin films

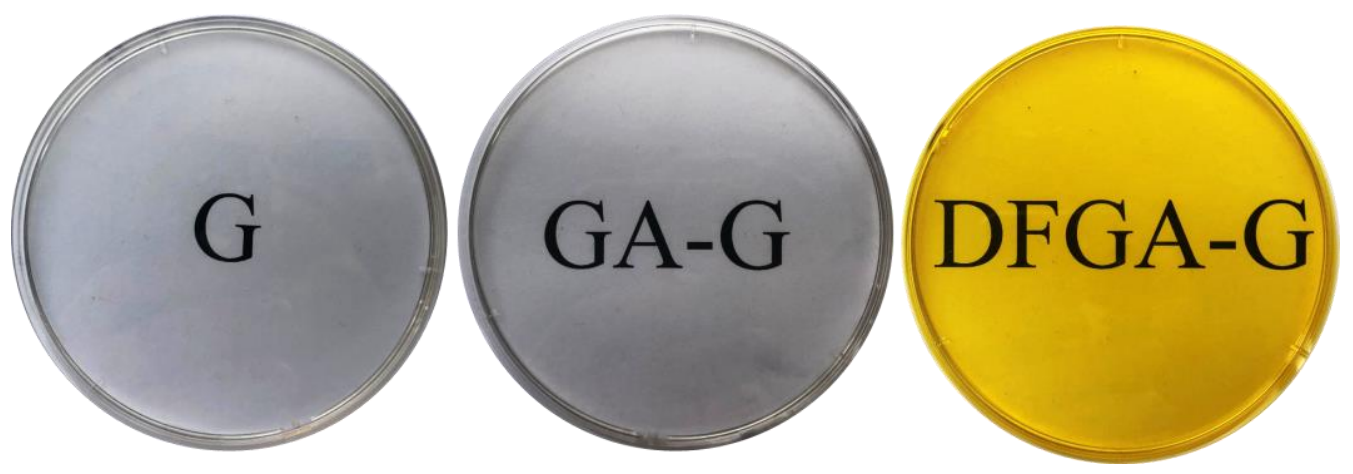

Figure S10. Photos of different gelatin films.

NMR spectra of blank gelatin film 


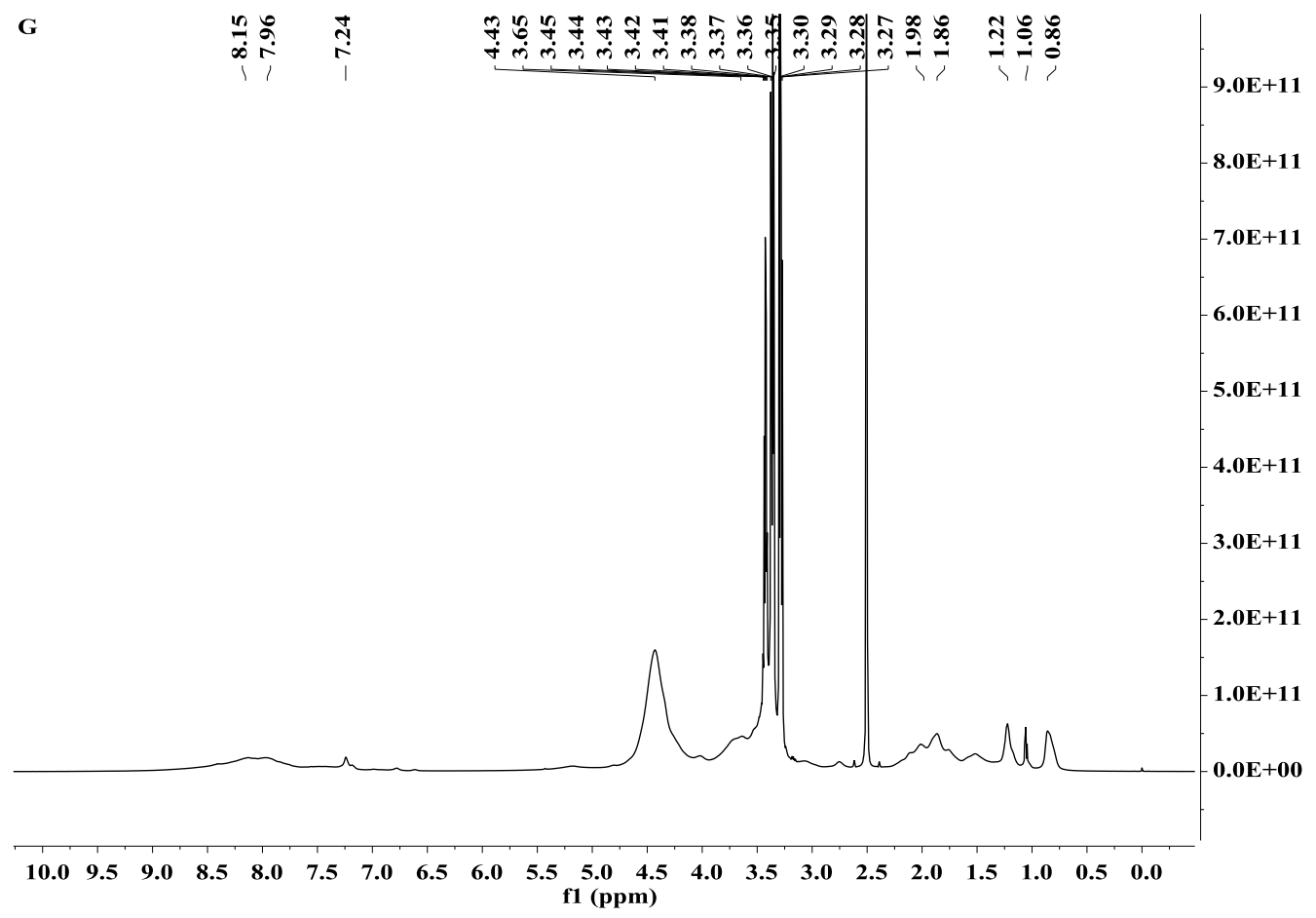

Figure S11. ${ }^{1} \mathrm{H}$ NMR spectra of blank gelatin film.

NMR spectra of gallic acid composite gelatin film

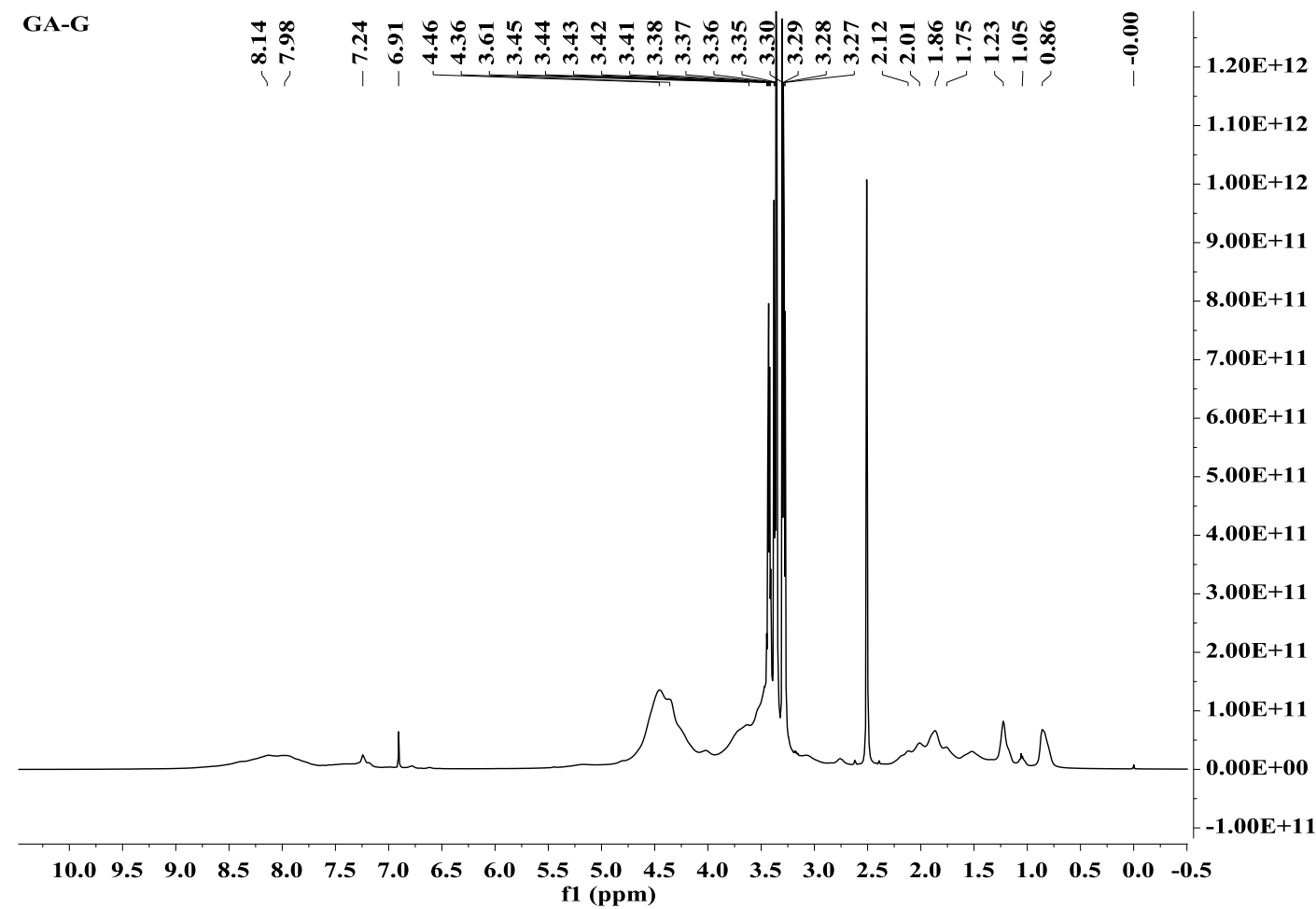

Figure S12. ${ }^{1} \mathrm{H}$ NMR spectra of gallic acid composite gelatin film.

\section{NMR spectra of modified gallic acid crosslinked gelatin film}




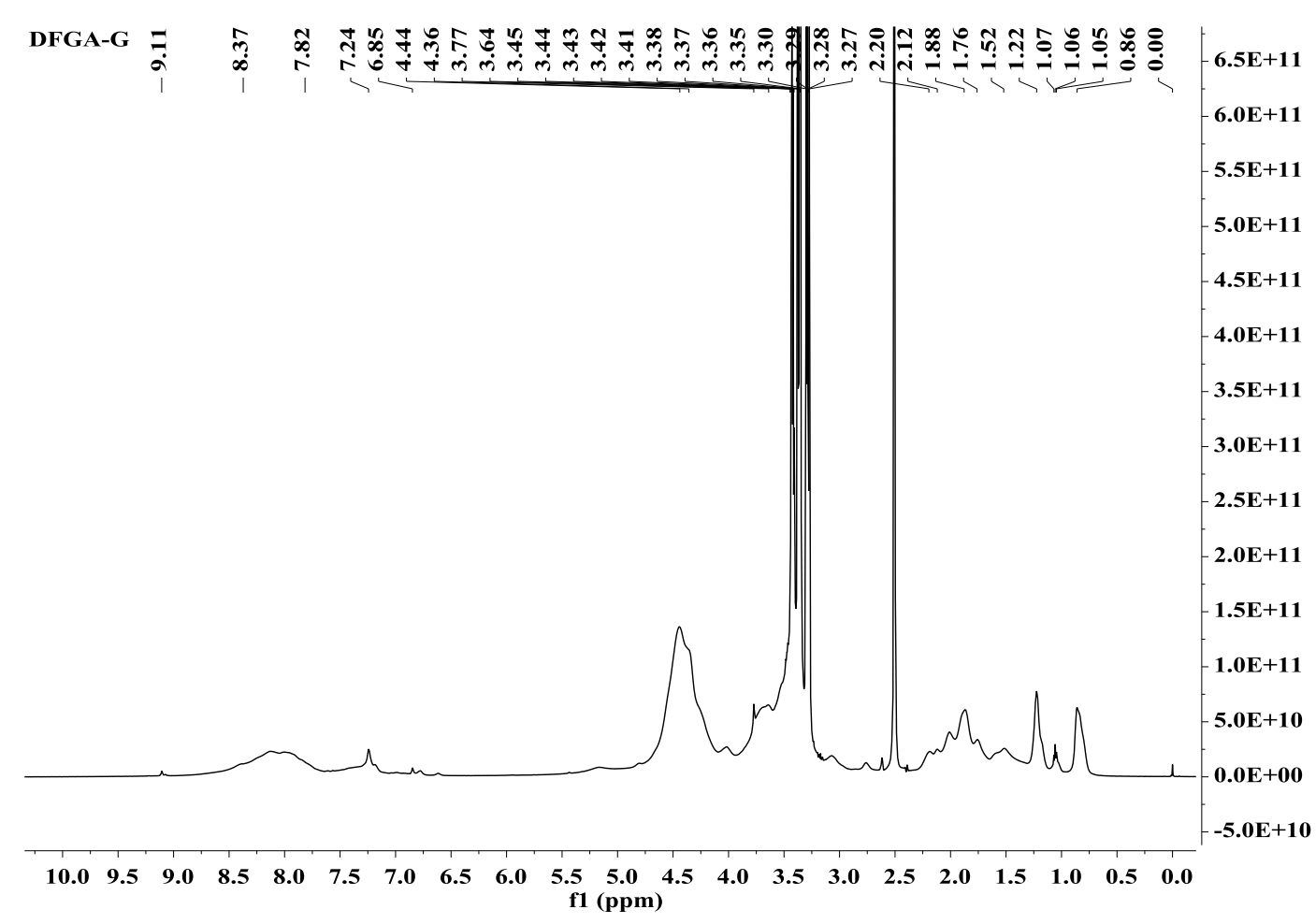

Figure S13. ${ }^{1} \mathrm{H}$ NMR spectra of modified gallic acid crosslinked gelatin film.

\section{Crosslinking mechanism model by modified gallic acid and glycine}

According to the optimal addition dosage of modified gallic acid (DFGA) in the process of crosslinking gelatin, $3 \mathrm{~mL}$ of $\mathrm{D}_{2} \mathrm{O}$ and $100 \mathrm{mg}$ of glycine were added to a $10 \mathrm{~mL}$ glass reaction flask, and $10 \mathrm{mg}$ of DFGA was added after mixing. Kept stirring for $60 \mathrm{~min}$ at $60{ }^{\circ} \mathrm{C}$. After the reaction was completed, $0.6 \mathrm{~mL}$ of the DFGA-glycine solution was added to a $6 \mathrm{~mm}$ diameter nuclear magnetic tube for ${ }^{1} \mathrm{H}$ NMR spectra measurement. ${ }^{1} \mathrm{H}$ NMR (400 MHz, $\mathrm{D}_{2} \mathrm{O}$ ) $\delta: 10.27$ (s), 8.98 (s), 7.72 (s), 7.09 (s), 6.98 (s), 4.73 (s), $4.34(\mathrm{~s}), 3.94(\mathrm{~s}), 3.90(\mathrm{~s}), 3.59$ (s). 


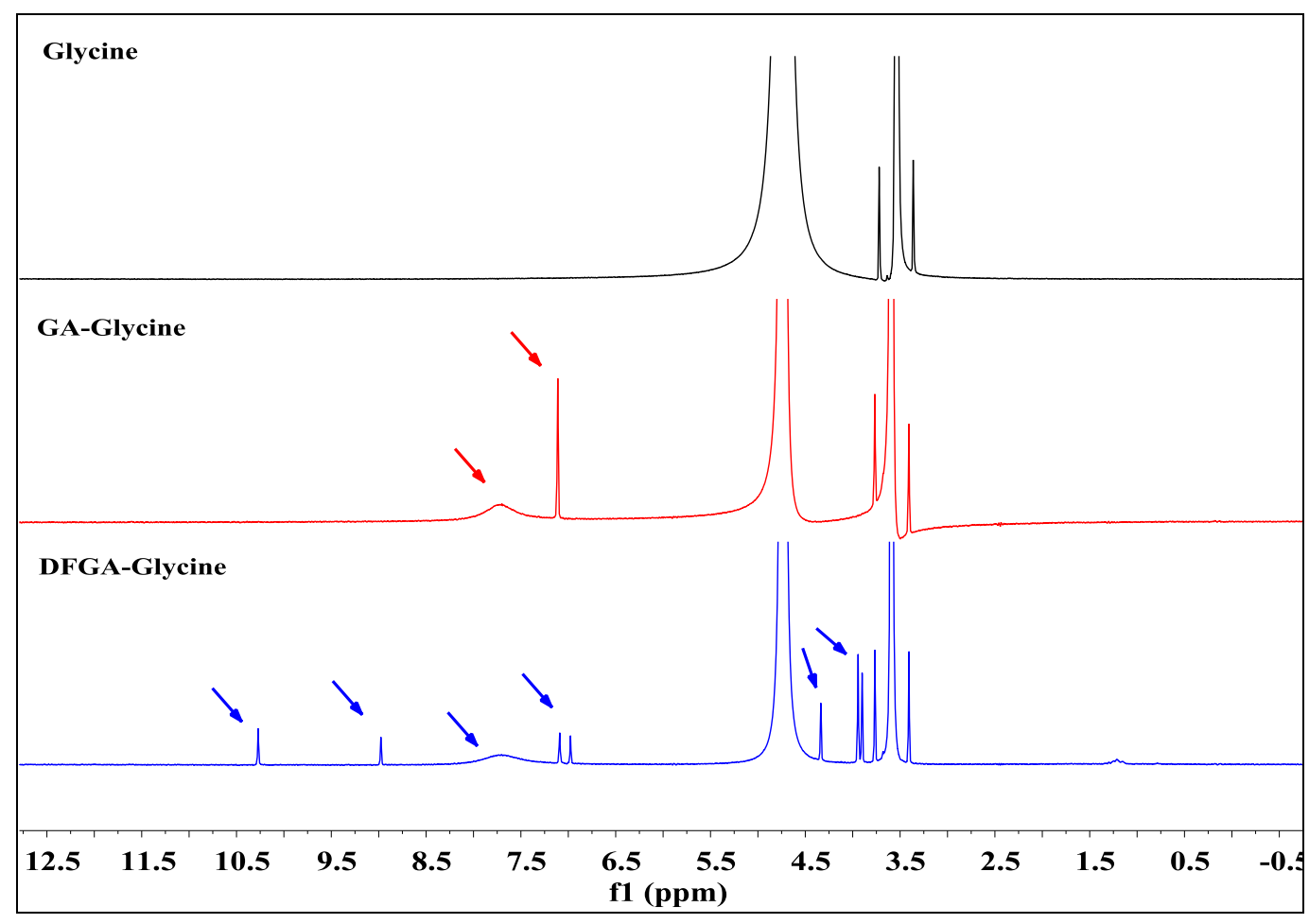

Figure S14. ${ }^{1} \mathrm{H}$ NMR spectra of different glycine complexes.

The ${ }^{1} \mathrm{H}$ NMR spectra of glycine, GA-glycine and DFGA-glycine complex are shown in Figure S14. Comparing the above spectra, it can be found that the peak with a chemical shift value of about $3.59 \mathrm{ppm}$ is the saturated hydrogen signal of the methylene carbon in glycine, and the peak located at $4.73 \mathrm{ppm}$ is the hydrogen signal of the amino group in glycine. The peak at $7.11 \mathrm{ppm}$ in the ${ }^{1} \mathrm{H}$ NMR spectra of the GA-glycine is the hydrogen signal on the aromatic ring of the gallic acid structure. The peak located at $7.09 \mathrm{ppm}$ in the ${ }^{1} \mathrm{H}$ NMR spectra of the DFGA-glycine is the hydrogen signal of the aromatic ring in the modified gallic acid structure that has not reacted with glycine. The chemical shift value at $6.98 \mathrm{ppm}$ is the hydrogen signal on the aromatic ring after the reaction of modified gallic acid and glycine. The aldehyde group signal of the modified gallic acid structure that did not react with glycine was detected at the chemical shift value of $10.27 \mathrm{ppm}$. The peak of the chemical shift value at $8.98 \mathrm{ppm}$ is the hydrogen signal of the Schiff base structure formed by the reaction of modified gallic acid with the amino group in glycine. The peak of the chemical shift value at $4.34 \mathrm{ppm}$ is the hydrogen signal on the methylene carbon in the glycine structure after the reaction. The chemical shift value increases due to the 
electron withdrawing effect of the formed Schiff base structure. The peaks of the chemical shift values at $3.90 \mathrm{ppm}$ and $3.94 \mathrm{ppm}$ are the hydrogen signals of the methoxy group in the modified gallic acid structure. Therefore, by analyzing the ${ }^{1} \mathrm{H}$ NMR spectra of different glycine complexes, the reaction mechanism of modified gallic acid and glycine can be obtained as shown in Figure S15.<smiles>NCC(=O)O</smiles>
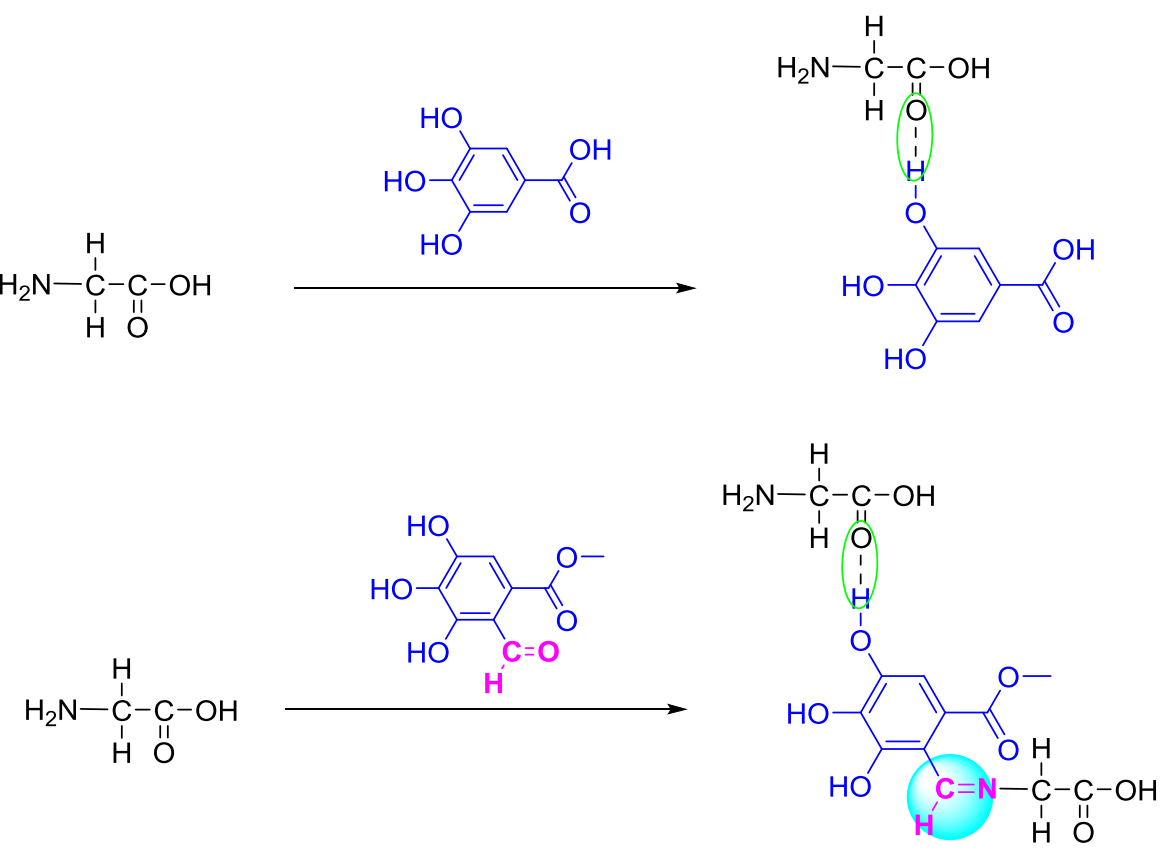

Figure S15. The reaction mechanism of modified gallic acid and glycine.

\section{Degradation of DFGA-G by enzyme}

Method of enzyme degradation. A commercially available protease was used for enzymolysis of DFGA-G. The sample was cut into pieces of $2 \mathrm{~cm} \times 2 \mathrm{~cm}$ and dried at $50{ }^{\circ} \mathrm{C}$ to a constant weight for later use. Prepare $20 \mathrm{u} \cdot \mathrm{mL}^{-1}$ protease solution with deionized water and activate it at $28{ }^{\circ} \mathrm{C}$ for $10 \mathrm{~h}$. Take $15 \mathrm{~mL}$ of the activated protease solution into each sample bottle and keep enzymolysis for $0.5 \mathrm{~h}, 1.0 \mathrm{~h}$ and $1.5 \mathrm{~h}$ at $28{ }^{\circ} \mathrm{C}$, respectively. Sample treated with deionized water was taken as blank control while polylactic acid film (PLA) was also treated as reference to compare the biodegradability of DFGA-G. After enzymolysis, the sample was taken out, rinsed with deionized water and dried to constant weight. The weight loss rate of the samples under different enzymolysis periods and the amino yield of the enzymolysis solution 
were measured, as well as the morphology change during the enzymolysis process of the DFGA-G.

The weight loss rate (Equation S1) and amino yield (Equation S2) were calculated as follows:

$$
\text { Weight loss rate }(\%)=\left(W_{0}-W_{1}\right) / W_{0}
$$

$W_{0}$ is the mass of the sample before enzymolysis, $\mathrm{g} ; W_{1}$ is the mass of the sample after enzymolysis, $g$.

$$
\text { Amino yield }\left(\mathrm{mg} \cdot \mathrm{g}^{-1}\right)=M / W_{0}
$$

$M$ is the amount of amino groups determined by the ninhydrin method in the degradation solution of the sample (the protease solution without sample as a blank), $\mathrm{mg} ; W_{0}$ is the mass of the sample before enzymolysis, $\mathrm{g}$.

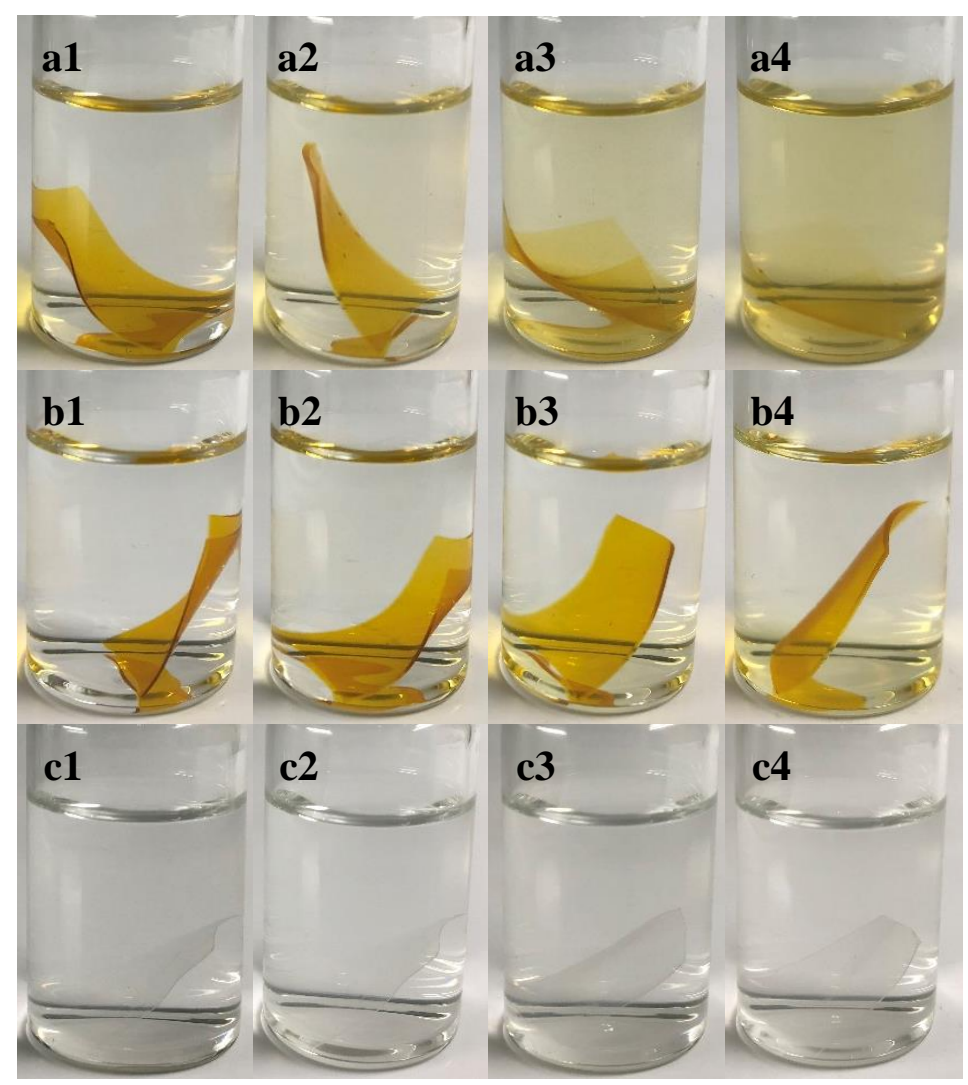

Figure S16. Enzymatic hydrolysis photos of different samples: a1, a2, a3, and a4 are the DFGA-G treated in protease solution for $0 \mathrm{~h}, 0.5 \mathrm{~h}, 1.0 \mathrm{~h}$, and $1.5 \mathrm{~h}$, respectively; b1, b2, b3, and b4 are the DFGA-G treated in deionized water for $0 \mathrm{~h}, 0.5 \mathrm{~h}, 1.0 \mathrm{~h}$, and $1.5 \mathrm{~h}$, respectively; $\mathrm{c} 1, \mathrm{c} 2, \mathrm{c} 3$, and $\mathrm{c} 4$ are the PLA in protease solution for $0 \mathrm{~h}, 0.5$ $\mathrm{h}, 1.0 \mathrm{~h}$, and $1.5 \mathrm{~h}$, respectively. 


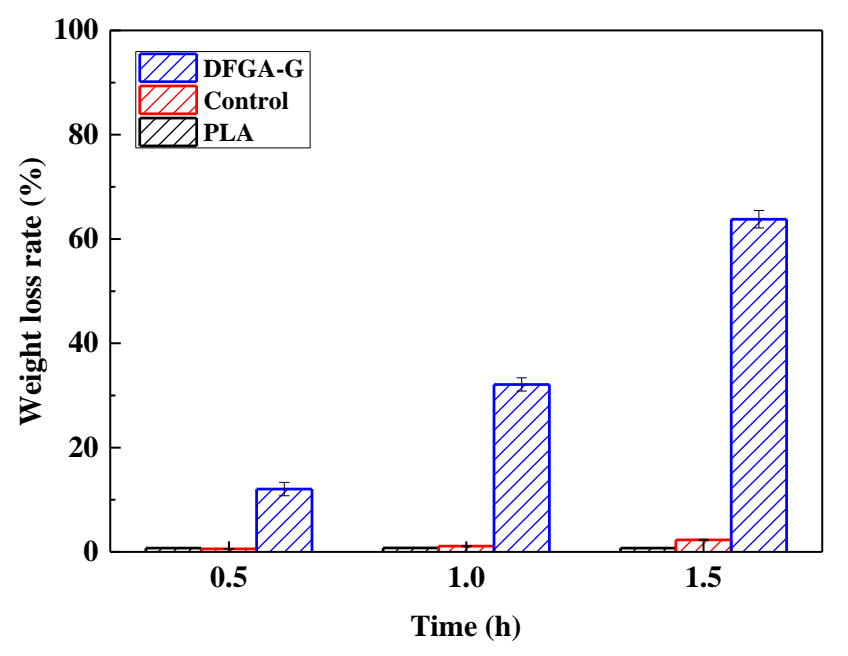

Figure S17. Weight loss rate of different samples.

The weight loss of different samples after enzymolysis. As an important auxiliary agent in industrial production, protease is widely used in the catalytic hydrolysis of proteins and polypeptides. ${ }^{1}$ The photos of DFGA-G in protease solution for $0 \mathrm{~h}, 0.5 \mathrm{~h}$, $1.0 \mathrm{~h}$, and $1.5 \mathrm{~h}$ are shown in Figure S16, and the weight loss rate of different samples is shown in Figure S17, which can be seen that DFGA-G has been degraded significantly under enzymolysis. As a common proteolytic enzyme, protease can break the peptide bond in the protein structure, and hydrolyze large-molecule protein substances. ${ }^{2}$ With enzymolysis for $0.5 \mathrm{~h}$ (a2), part of the peptide bonds in the DFGA-G were hydrolyzed and dissolved, resulting in a weight loss rate of $12.05 \%$. The breakage of the gelatin peptide bond somehow promoted the penetration of water molecules into the film, causing further swelling. ${ }^{3}$ When the enzymolysis continued to $1.0 \mathrm{~h}(\mathrm{a} 3)$, greater weight loss $(32.10 \%)$ was observed. When it was degraded to $1.5 \mathrm{~h}$ (a4), the spatial structure of the gelatin film was destroyed, the gelatin molecules in the film were hydrolyzed and dissolved out, and the weight loss of the gelatin film obviously raised to $63.80 \%$. From the results of the control group, basically no degradation was found in deionized water treatment, while at $1.5 \mathrm{~h}(\mathrm{~b} 4)$, there is only slight swelling and weight loss caused by the dissolution of some uncross linked gelatin molecules (2.3\%). After immersing PLA in the protease solution for $1.5 \mathrm{~h}(\mathrm{c} 4)$, the appearance structure and weight loss rate of the film did not change significantly. 


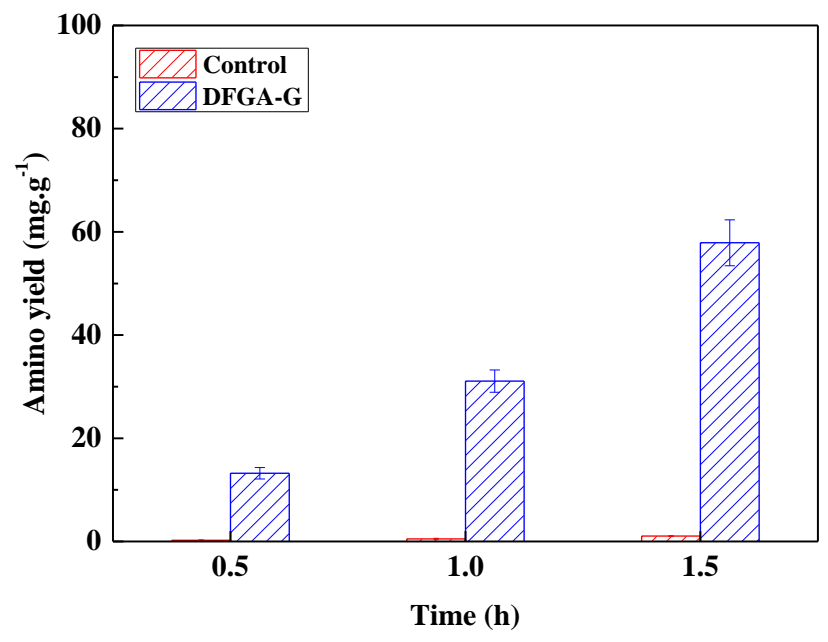

Figure S18. Amino yield of different enzymolysis time.

Amino yields of different samples after enzymolysis. The yields of amino groups after enzymolysis of different samples are shown in Figure S18. It can be seen that the yields of amino groups in the enzymatic hydrolysis DFGA-G solution of varied significantly with different enzymolysis periods. When DFGA-G was degraded in the protease solution for $0.5 \mathrm{~h}$, part of the peptide bonds in the gelatin molecule was hydrolyzed and some free amino groups were released into the solution. The yield of the amino groups detected in the enzymatic hydrolysis solution was $13.21 \mathrm{mg} \cdot \mathrm{g}^{-1}$. With the extension of the enzymolysis time to $1.0 \mathrm{~h}$, the peptide bonds of the gelatin molecule were gradually broken down, consequently more amino groups were detected in the enzymatic hydrolysis solution $\left(31.07 \mathrm{mg} \cdot \mathrm{g}^{-1}\right)$. Finally, when the degradation progressed to $1.5 \mathrm{~h}$, the peptide bonds in the gelatin structure were hydrolyzed in a large amount, and the yield of amino groups in the enzymatic hydrolysis solution reached to $57.89 \mathrm{mg} \cdot \mathrm{g}^{-1}$. When DFGA-G was treated with deionized water, the amino content in the water did not change significantly, only a few uncross linked gelatin molecules was dissolved into the solution caused by the swelling of the gelatin film, some in the aqueous solution were detected to be 1.05 $\mathrm{mg} \cdot \mathrm{g}^{-1}$.

The micromorphology of different samples after enzymolysis. The dried samples after enzymolysis were observed using SEM with spraying with gold particles on the surface. The morphologies of different samples after enzymolysis were shown in Figure S19. After $0.5 \mathrm{~h}$ of degradation, the surface of the DFGA-G became rough as 
the gelatin molecular chain was hydrolyzed by protease. When the enzymatic hydrolysis reached $1.0 \mathrm{~h}$, the gelatin molecular chain was further hydrolyzed, causing a small amount of gelatin fragments to fall off. When the enzymatic hydrolysis reached $1.5 \mathrm{~h}$, due to the massive hydrolysis of the gelatin molecular chain, the spatial structure of the film was mostly destroyed and broken, leading to the fell off of a large number of flocculent fragments. The surface of DFGA-G in deionized water and PLA in protease solution did not change significantly. Clearly, protease solution can hydrolyze the gelatin molecular chain, thereby destroying the spatial structure of the film and causing significant degradation. In addition, DFGA-G also showed great degradability under microbial degradation and activated sludge composting. The specific information are displayed in the supporting information.

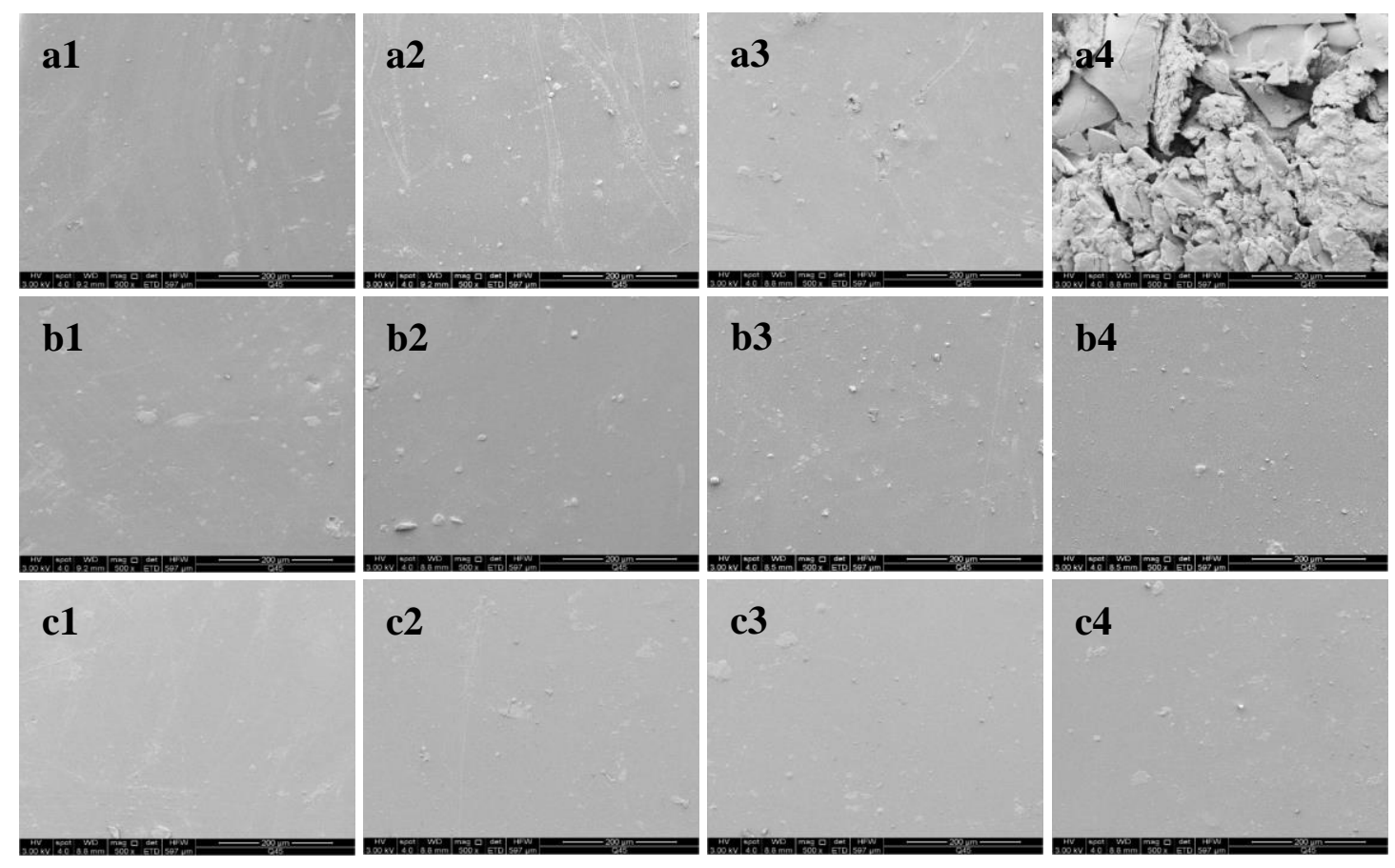

Figure S19. SEM of different samples after enzymolysis: a1, a2, a3, and a4 are the surface micromorphology (500x) of DFGA-G after treated in protease solution for $0 \mathrm{~h}$, $0.5 \mathrm{~h}, 1.0 \mathrm{~h}$, and $1.5 \mathrm{~h}$, respectively; b1, b2, b3, and b4 are the surface micromorphology $(500 \times)$ of DFGA-G after treated in deionized water for $0 \mathrm{~h}, 0.5 \mathrm{~h}$, $1.0 \mathrm{~h}$, and $1.5 \mathrm{~h}$, respectively; c1, c2, c3, and c4 are the surface micromorphology (500x) of PLA after treated in protease solution for $0 \mathrm{~h}, 0.5 \mathrm{~h}, 1.0 \mathrm{~h}$, and $1.5 \mathrm{~h}$, respectively. 


\section{Degradation of DFGA-G by microorganism}

Method of microbial degradation. As a common fermentation engineering yeast, S. cerevisiae can produce a variety of active substances during its growth and metabolism, and it is widely used in daily life and industrial production. ${ }^{4}$ In this study, S. cerevisiae was used for microbial degradation of DFGA-G. The sample was cut into pieces of $2 \mathrm{~cm} \times 2 \mathrm{~cm}$ and dried at $50{ }^{\circ} \mathrm{C}$ to a constant weight for later use. A $1 \%$ mass concentration (sterile normal saline) of $S$. cerevisiae suspension was prepared with immobilized S. cerevisiae $\left(10^{8} \mathrm{cfu} \cdot \mathrm{g}^{-1}\right)$ and activated at $28{ }^{\circ} \mathrm{C}$ for $10 \mathrm{~h}$. Then DFGA-G tablet was exposed into $15 \mathrm{~mL}$ of the activated supernatant and incubated at $28{ }^{\circ} \mathrm{C}$ for $2 \mathrm{~h}, 4 \mathrm{~h}$, and $6 \mathrm{~h}$, respectively. Sample treated with normal saline was taken as blank control while polylactic acid film (PLA) was also treated with $S$. cerevisiae as reference to compare the biodegradability of DFGA-G. After microbial degradation, the sample was taken out, rinsed with deionized water and dried to constant weight. The weight loss rate of samples and the yield of amino groups in the microbial degradation solution of different degradation periods were determined, as well as the morphology observation of the DFGA-G during the degradation process.

The weight loss rate (Equation S3) and amino yield (Equation S4) were calculated as follows:

$$
\text { Weight loss rate }(\%)=\left(W_{0}-W_{1}\right) / W_{0}
$$

$W_{0}$ is the mass of the sample before microbial degradation, $\mathrm{g}$; $W_{1}$ is the mass of the sample after microbial degradation, g.

$$
\text { Amino yield }\left(\mathrm{mg} \cdot \mathrm{g}^{-1}\right)=M / W_{0}
$$

$M$ is the amount of amino groups determined by the ninhydrin method in the degradation solution of the sample (the supernatant without adding the sample as a blank), $\mathrm{mg} ; W_{0}$ is the mass of the sample before microbial degradation, $\mathrm{g}$. 


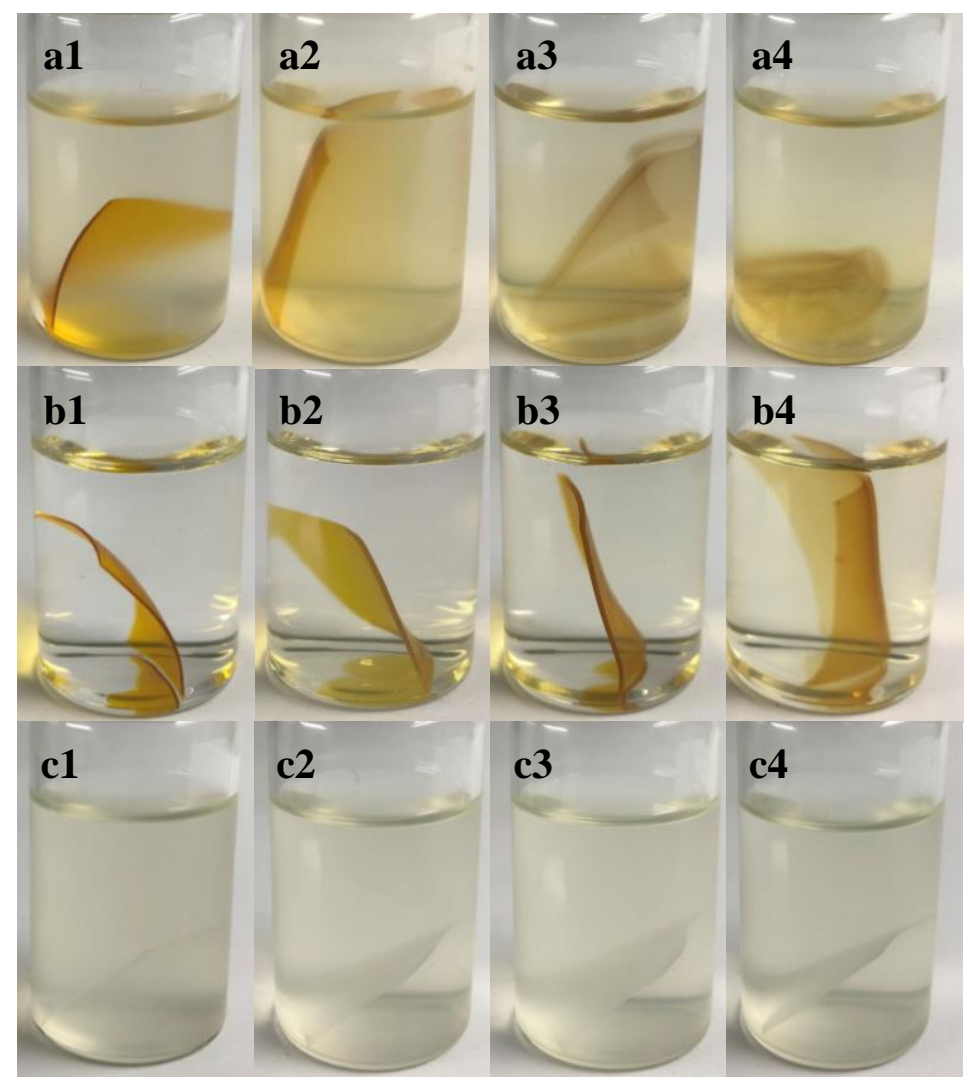

Figure S20. Microbial degradation photos of different samples: a1, a2, a3, and a4 are the DFGA-G treated in suspension for $0 \mathrm{~h}, 2 \mathrm{~h}, 4 \mathrm{~h}$, and $6 \mathrm{~h}$, respectively; b1, b2, b3, and b4 are the DFGA-G treated in normal saline for $0 \mathrm{~h}, 2 \mathrm{~h}, 4 \mathrm{~h}$, and $6 \mathrm{~h}$, respectively; $\mathrm{c} 1, \mathrm{c} 2, \mathrm{c} 3$, and $\mathrm{c} 4$ are the PLA in suspension for $0 \mathrm{~h}, 2 \mathrm{~h}, 4 \mathrm{~h}$, and $6 \mathrm{~h}$, respectively.

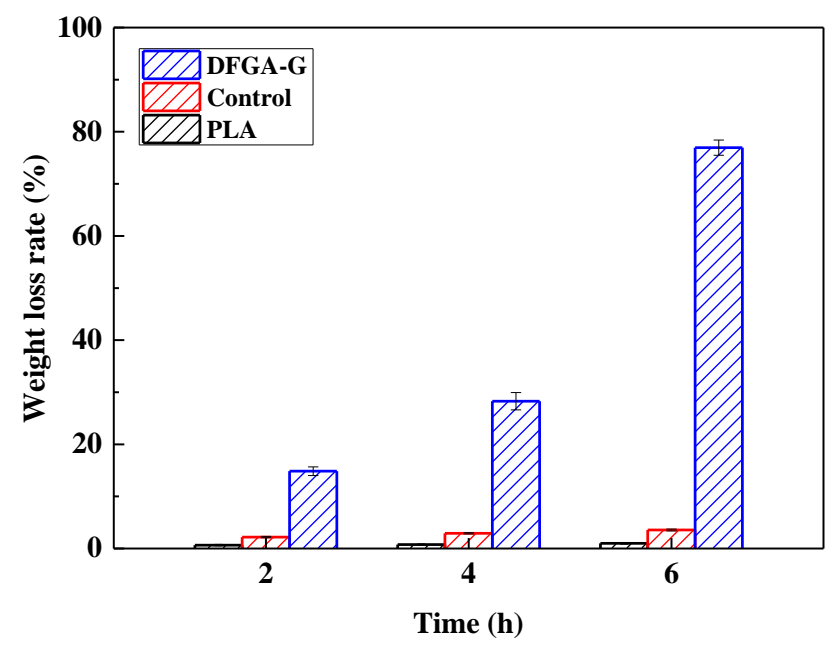

Figure S21. Weight loss rate of different samples.

Weight loss of different samples after microbial degradation. The digital photos of DFGA-G under $S$. cerevisiae treatment for $0 \mathrm{~h}, 2 \mathrm{~h}, 4 \mathrm{~h}$, and $6 \mathrm{~h}$ are shown in Figure S20, and the weight loss rate of different samples is shown in Figure S21, 
which showed significant degradation along with time. The microbial degradation of DFGA-G film should be due to these two mechanisms: On the one hand, microorganisms can produce a series of hydrolase like protease during their growth, which promotes the breakdown of the peptide linkage. On the other hand, microorganisms could invade the internal structure of substances by water swelling and former microbial erosion, therefore caused physical deterioration and accelerating degradation. ${ }^{5}$ After being degraded for $2 \mathrm{~h}$, an obvious swelling was observed while the weight loss rate was $14.85 \%$. Further hydrolysis and fragmentation of DFGA-G by $S$. cerevisiae continued and weight loss rate significantly increased to $28.27 \%$ after treatment for $4 \mathrm{~h}$. When it was degraded for $6 \mathrm{~h}$, with the proliferation of $S$. cerevisiae $\left(5.3 \times 10^{9} \mathrm{cfu} \cdot \mathrm{g}^{-1}\right)$ and the production of more hydrolytic enzymes, the weight loss rate reached the maximum of $76.95 \%$. Comparing with the control group, basically no degradation was found in normal saline treatment, only showed obvious swelling at 6 h (b4) with a weight loss of $3.56 \%$ caused by the release of uncross linked gelatin molecules. No significant change was found on the appearance structure and weight loss rate in the PLA treatments.

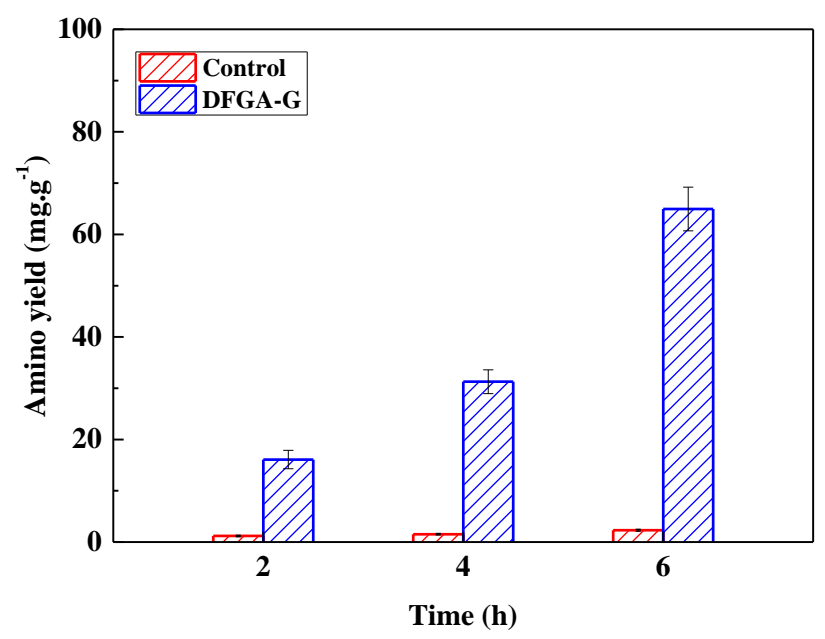

Figure S22. Amino yield of different degradation samples.

Amino yields of different samples after microbial degradation. The yields comparison of amino groups after degradation of different samples in the S. cerevisiae suspension of different treatments are shown in Figure S22. It can be seen that the yield of amino groups in the DFGA-G solution of varied significantly with different 
degradation periods. When DFGA-G was treated for $2 \mathrm{~h}$, part of the peptide bonds in the gelatin molecule was hydrolyzed, producing some free amino groups (16.09 $\left.\mathrm{mg} \cdot \mathrm{g}^{-1}\right)$. The amino groups yield increased to $31.27 \mathrm{mg} \cdot \mathrm{g}^{-1}$ in treatment of $4 \mathrm{~h}$. Finally, when the degradation progressed to $6 \mathrm{~h}$, the peptide bonds in the gelatin were hydrolyzed in large quantities, giving a yield of amino groups of $64.95 \mathrm{mg} \cdot \mathrm{g}^{-1}$. Meanwhile, the amino group content did not change significantly in the control, only a few uncross linked gelatin molecules $\left(2.31 \mathrm{mg} \cdot \mathrm{g}^{-1}\right)$ was dissolved into the solution caused by swelling.

Micromorphology of different samples after microbial degradation. The dried samples after $S$. cerevisiae degradation were observed using SEM with spraying with gold particles on the surface. The morphologies of different samples after microbial degradation were shown in Figure S23. During the degradation process, DFGA-G played as the necessary carbon and nitrogen sources for the growth of S. cerevisiae, proving its biocompatibility and bioavailability. After $2 \mathrm{~h}$ of degradation, the surface of the film showed signs of microbial erosion. When it was cultured for $4 \mathrm{~h}$, the film had a large-area of microbial erosion, and the gelatin molecules in the film structure were further hydrolyzed according to the amino data. When cultured for $6 \mathrm{~h}$, the growth of $S$. cerevisiae inside the gelatin film and the hydrolysis of gelatin molecules by $S$. cerevisiae produced enzymes lead to an obvious degradation and a large amount of flocculent debris (a4) while the DFGA-G film in the normal saline only has partial breakage (b4) because of water swelling. However, the S. cerevisiae treatment showed no effect on the PLA film after soaking for $6 \mathrm{~h}$. Therefore, S. cerevisiae can efficiently biodegrade DFGA-G by rupturing gelatin into amino acids thus completely destroying the spatial structure of the film. 


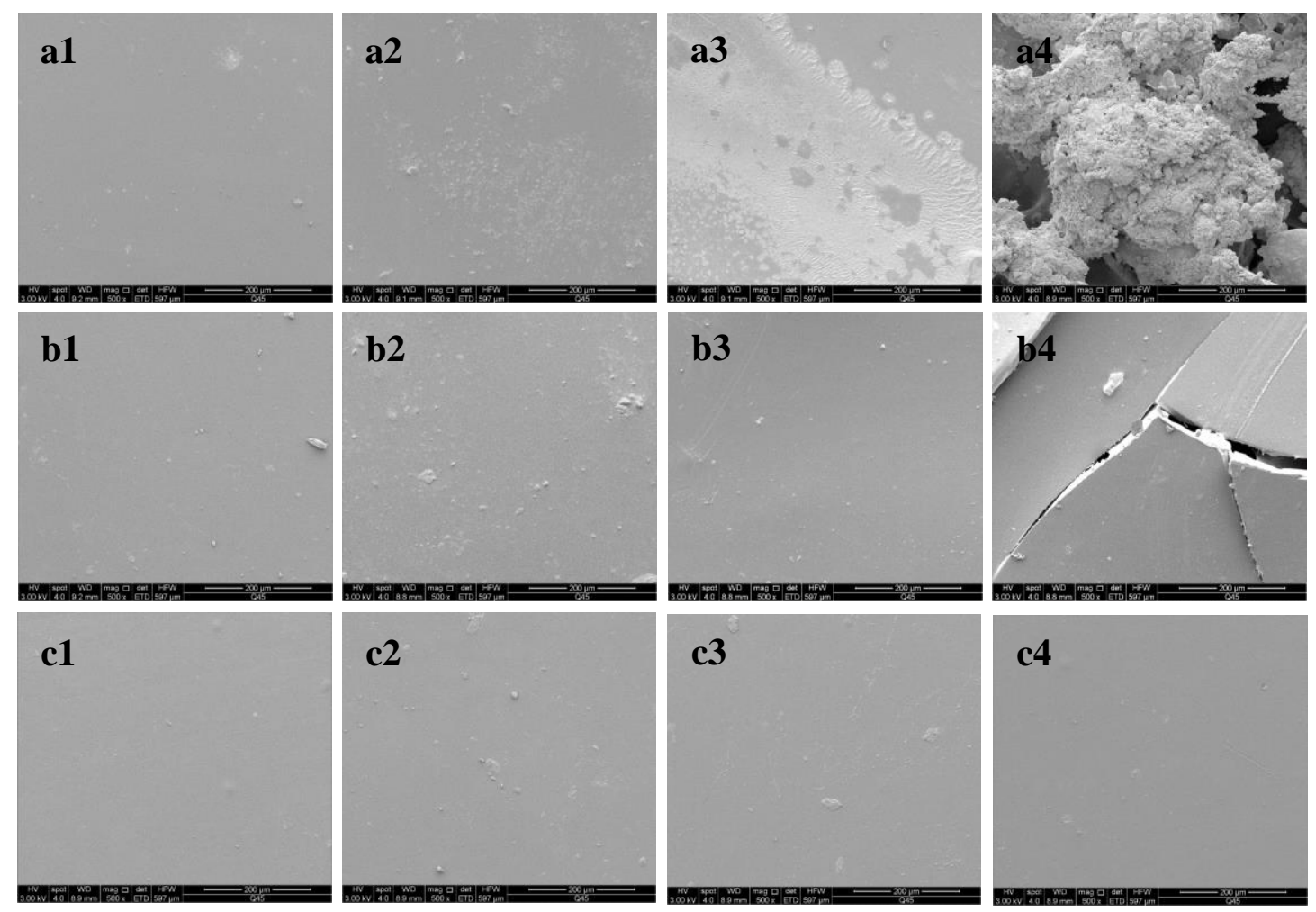

Figure S23. SEM of different samples after microbial degradation: a1, a2, a3, and a4 are the surface micromorphology (500x) of DFGA-G after treated in suspension for 0 $\mathrm{h}, 2 \mathrm{~h}, 4 \mathrm{~h}$, and $6 \mathrm{~h}$, respectively; b1, b2, b3, and b4 are the surface micromorphology (500x) of DFGA-G after treated in normal saline for $0 \mathrm{~h}, 2 \mathrm{~h}, 4 \mathrm{~h}$, and $6 \mathrm{~h}$, respectively; c1, c2, c3, and c4 are the surface micromorphology (500x) of PLA after treated in suspension for $0 \mathrm{~h}, 2 \mathrm{~h}, 4 \mathrm{~h}$, and $6 \mathrm{~h}$, respectively.

\section{Degradation of DFGA-G by activated sludge composting}

Method of activated sludge composting. Activated sludge contains abundant microbial populations, which can be used for the biodegradation of many substances. ${ }^{6}$ In order to simulate biodegradation in natural conditions, activated sludge composting was conducted for the biodegradation of DFGA-G. The sample was cut into pieces of $2 \mathrm{~cm} \times 2 \mathrm{~cm}$ and dried at $50{ }^{\circ} \mathrm{C}$ to constant weight for later use. The activated sludge was firstly activated at $28{ }^{\circ} \mathrm{C}$ for $10 \mathrm{~h}$, then filled into flat dish. The tested film was covered on the surface of the activated sludge and incubated at $28{ }^{\circ} \mathrm{C}$ for $10 \mathrm{~h}, 20 \mathrm{~h}$, and $30 \mathrm{~h}$, respectively. Sample treated with autoclaved activated sludge was taken as blank control while polylactic acid film (PLA) was also treated as reference to 
evaluate the biodegradability of DFGA-G. After degradation, the sample was taken out, rinsed with deionized water and dried to constant weight. The weight loss rates and the morphologies of the films under different incubation times were analyzed as mentioned above.

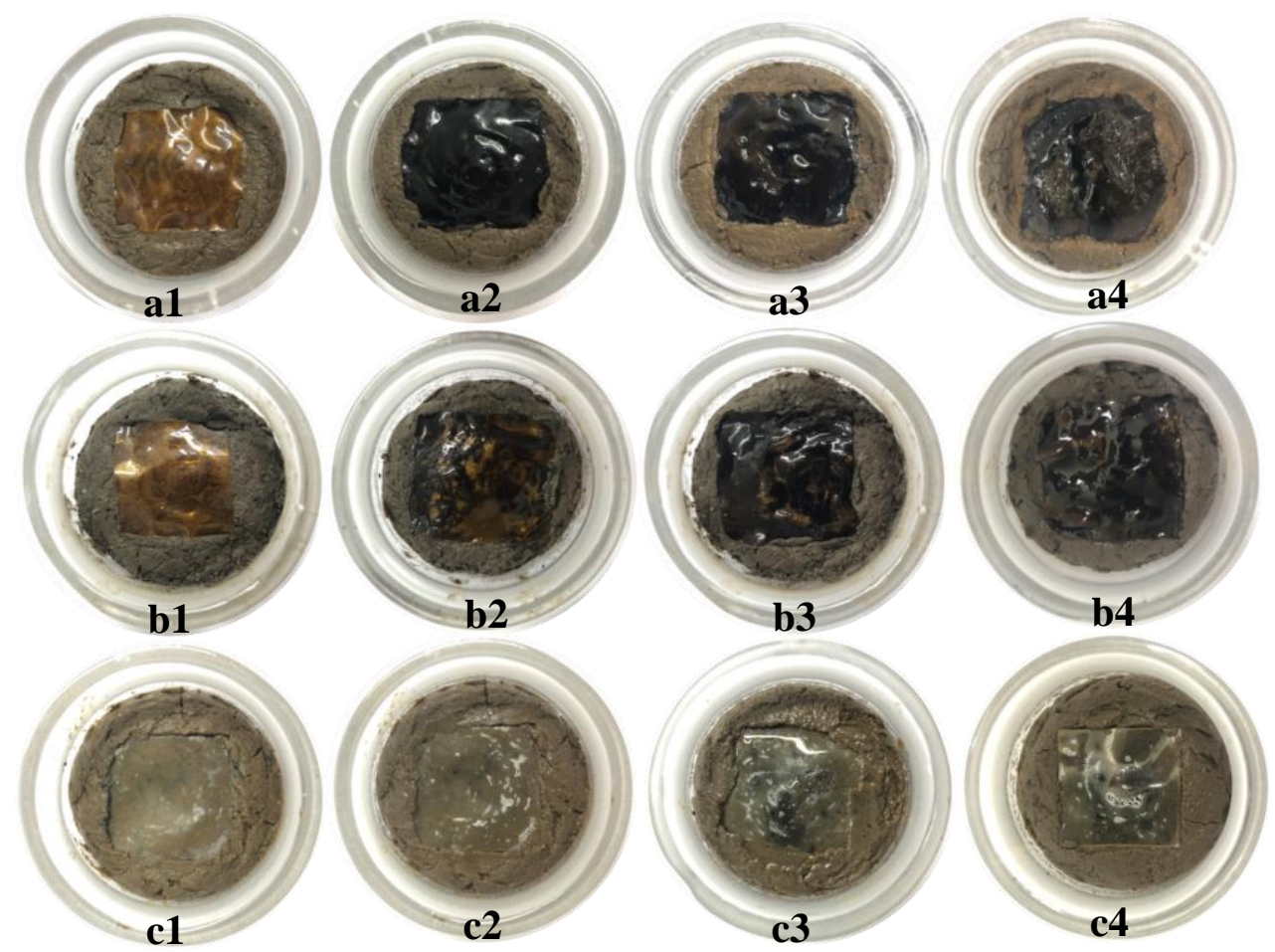

Figure S24. Activated sludge degradation photos of different samples: a1, a2, a3, and a4 are the DFGA-G treated with activated sludge for $0 \mathrm{~h}, 10 \mathrm{~h}, 20 \mathrm{~h}$, and $30 \mathrm{~h}$, respectively; b1, b2, b3, and b4 are the DFGA-G treated with autoclaved activated sludge for $0 \mathrm{~h}, 10 \mathrm{~h}, 20 \mathrm{~h}$, and $30 \mathrm{~h}$, respectively; c1, c2, c3, and c4 are the PLA treated with activated sludge for $0 \mathrm{~h}, 10 \mathrm{~h}, 20 \mathrm{~h}$, and $30 \mathrm{~h}$, respectively.

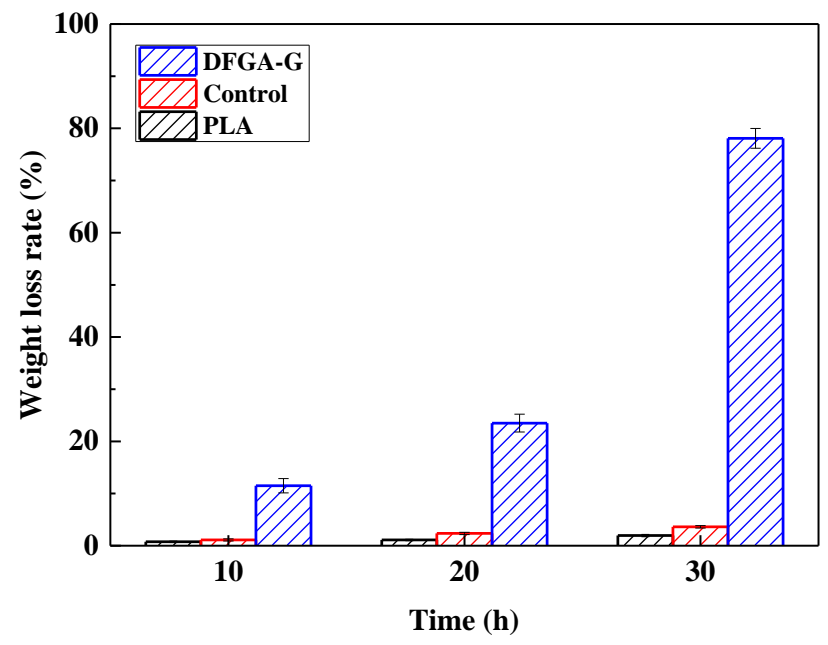


Figure S25. Weight loss rate of different samples.

Weight loss of different samples after activated sludge degradation. The digital photos of DFGA-G treated by activated sludge for $0 \mathrm{~h}, 10 \mathrm{~h}, 20 \mathrm{~h}$, and $30 \mathrm{~h}$ are shown in Figure S24, and the weight loss rate of different samples is shown in Figure S25. Clearly, the weight loss rate increase from $11.49 \%$ at $10 \mathrm{~h}$ to $78.08 \%$ at $30 \mathrm{~h}$, indicating an enhancing and efficient biodegradation along with the treatment period, which was due to the structure damage by the corrosion of microorganisms in the activated sludge. On the contrary, in the control, the DFGA-G treated by inactivated sludge only resulted in a weight loss of $3.62 \%$, proving the effect of microbial degradation. However, PLA film in activated sludge composting only had a weight loss of $1.95 \%$, indicating its weak biodegradable property.

Micromorphology of different samples after activated sludge degradation. The SEM photos of different samples after activated sludge treatment were shown in Figure S26. As can be seen, DFGA-G was degraded under the action of microorganisms in the activated sludge, and the surface of the film showed signs of obvious microbial erosion. After culturing for $20 \mathrm{~h}$, larger-area of microbial erosion and cracks appeared. When it was cultured for $30 \mathrm{~h}$, due to the degradation of gelatin molecules by microorganisms in the activated sludge, the film broke down and produced a large amount of flocculent debris. After treating DFGA-G in the inactivated sludge for $30 \mathrm{~h}$, no morphology change was observed while only slight traces of microbial erosion appeared on the PLA film treated in activated sludge. Clearly, the microorganisms rich in activated sludge can biodegrade DFGA-G. 

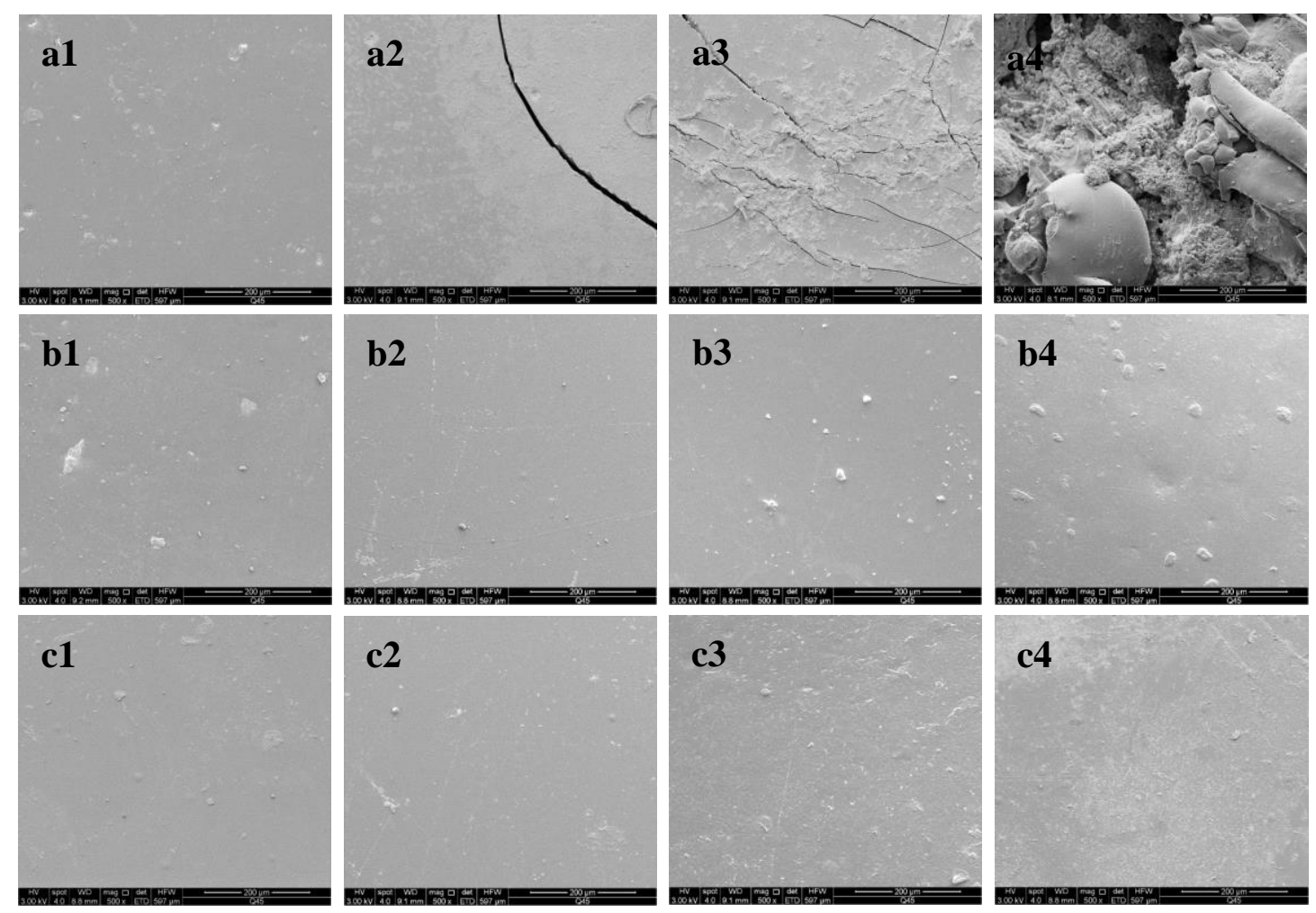

Figure S26. SEM of different samples after activated sludge degradation: a1, a2, a3, and a4 are the surface micromorphology (500x) of DFGA-G after treated with activated sludge for $0 \mathrm{~h}, 10 \mathrm{~h}, 20 \mathrm{~h}$, and $30 \mathrm{~h}$, respectively; b1, b2, b3, and b4 are the surface micromorphology (500x) of DFGA-G after treated with autoclaved activated sludge for $0 \mathrm{~h}, 10 \mathrm{~h}, 20 \mathrm{~h}$, and $30 \mathrm{~h}$, respectively; c1, c2, c3, and c4 are the surface micromorphology (500x) of PLA after treated with activated sludge for $0 \mathrm{~h}, 10 \mathrm{~h}, 20 \mathrm{~h}$, and $30 \mathrm{~h}$, respectively.

\section{Degradation of DFGA-G by different $\mathrm{pH}$ solutions}

Method of activated sludge composting. The hydrolytic degradation ability of the prepared modified gallic acid crosslinked gelatin film was researched using a hydrochloric acid solution of $\mathrm{pH} 1.0$, an acetate buffer of $\mathrm{pH} 4.5$ and a phosphate buffer saline (PBS) of $\mathrm{pH} \mathrm{7.4.}{ }^{7}$ The sample was cut into $2 \mathrm{~cm} \times 2 \mathrm{~cm}$ pieces, dried to constant weight at $50{ }^{\circ} \mathrm{C}$, and then placed in a sample bottle. Added $18 \mathrm{~mL}$ of different $\mathrm{pH}$ solutions, and placed the sample bottles in an incubator at $37^{\circ} \mathrm{C}$. Within the set time, the sample is taken out of the solution, rinsed with deionized water and dried to constant weight. The weight loss rate of the sample under different hydrolysis 
time was measured to compare the hydrolytic degradation ability of the modified gallic acid crosslinked gelatin films in different $\mathrm{pH}$ solutions.

The weight loss rate (Equation S5) was calculated as follows:

$$
\text { Weight loss rate }(\%)=\left(W_{0}-W_{1}\right) / W_{0}
$$

$W_{0}$ is the mass of the sample before hydrolytic degradation, $\mathrm{g}$; $W_{1}$ is the mass of the sample after hydrolytic degradation, $\mathrm{g}$.

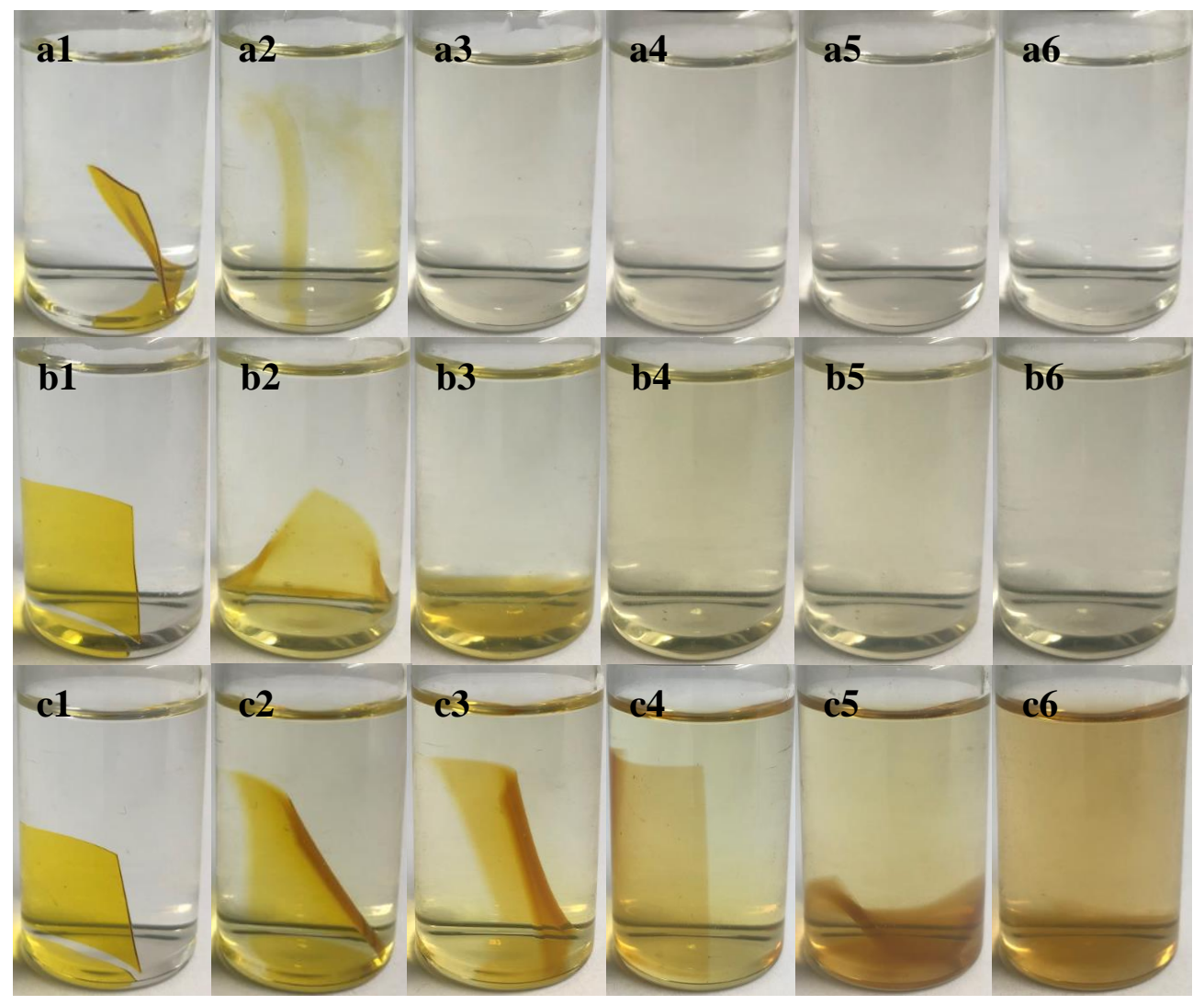

Figure S27. Hydrolytic degradation photos of modified gallic acid crosslinked gelatin film with different $\mathrm{pH}$ solutions: a1, a2, a3, a4, a5, and a6 are the film treated in a hydrochloric acid solution of $\mathrm{pH} 1.0$ for $0 \mathrm{~h}, 6 \mathrm{~h}, 12 \mathrm{~h}, 24 \mathrm{~h}, 36 \mathrm{~h}$ and $48 \mathrm{~h}$, respectively; b1, b2, b3, b4, b5, and b6 are the film treated in an acetate buffer of $\mathrm{pH}$ 4.5 for 0 h, $6 \mathrm{~h}, 12 \mathrm{~h}, 24 \mathrm{~h}, 36 \mathrm{~h}$ and 48 h, respectively; c1, c2, c3, c4, c5, and c6 are the film treated in a phosphate buffer saline of $\mathrm{pH} 7.4$ for $0 \mathrm{~h}$, and $6 \mathrm{~h}, 12 \mathrm{~h}, 24 \mathrm{~h}, 36 \mathrm{~h}$ and $48 \mathrm{~h}$, respectively. 


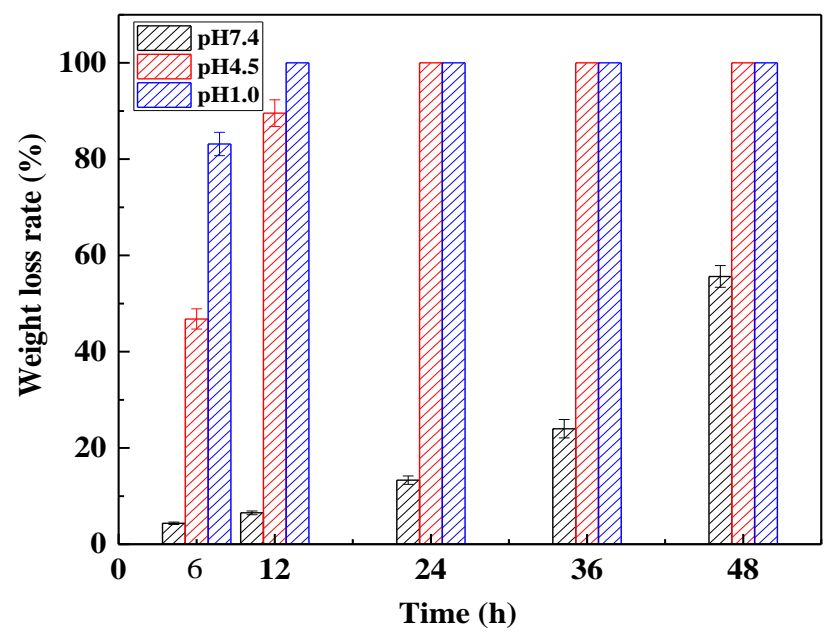

Figure S28. Weight loss rate of DFGA-G in different $\mathrm{pH}$ solutions.

The digital photos of DFGA-G in different $\mathrm{pH}$ solutions for $0 \mathrm{~h}, 6 \mathrm{~h}, 12 \mathrm{~h}, 24 \mathrm{~h}$, $36 \mathrm{~h}$, and $48 \mathrm{~h}$ are shown in Figure S27, and the weight loss rate is shown in Figure S28. The polypeptide molecular chains in gelatin are easily hydrolyzed in acidic solutions, causing its structure to be destroyed. ${ }^{8}$ Aldehydes can be crosslinked with the amino groups of gelatin molecules to improve the stability of gelatin films, but the Schiff base structure formed after crosslinking has a poor stability in acidic solutions. ${ }^{9}$ The modified gallic acid crosslinked gelatin film was obviously hydrolyzed in acid solution. After $6 \mathrm{~h}$ of hydrolysis, the weight loss rate of the gelatin film in the $\mathrm{pH} 1$ and $\mathrm{pH} 4.5$ solutions were $83.16 \%$ and $46.80 \%$, respectively. After $12 \mathrm{~h}$ of hydrolysis, the gelatin film was completely hydrolyzed in the $\mathrm{pH} 1$ solution, and the weight loss rate in the $\mathrm{pH} 4.5$ solution reached $89.57 \%$. In contrast, the crosslinking of aldehyde structure and amino groups of gelatin molecules significantly improved its stability in the $\mathrm{pH} 7.4$ solution, ${ }^{10}$ and the compact structure formed after crosslinking can inhibit the penetration of PBS. ${ }^{11}$ DFGA-G was hydrolyzed in a solution of $\mathrm{pH} 7.4$ for $48 \mathrm{~h}$, and its weight loss rate was only reached 55.63\%. The results of hydrolytic degradation showed that the DFGA-G degraded significantly in acidic solution, while it had a higher stability in PBS.

\section{The microscopic morphology of different gelatin films after swelled in water}

The pieces of different gelatin films $(2 \mathrm{~cm} \times 2 \mathrm{~cm})$ were immersed into deionized water at $25{ }^{\circ} \mathrm{C}$ for $48 \mathrm{~h}$ to swell completely. ${ }^{12}$ The swelled samples were freeze-dried 
after that, and the microscopic morphologies of them were observed by SEM. The experimental results are shown in Figure S29.
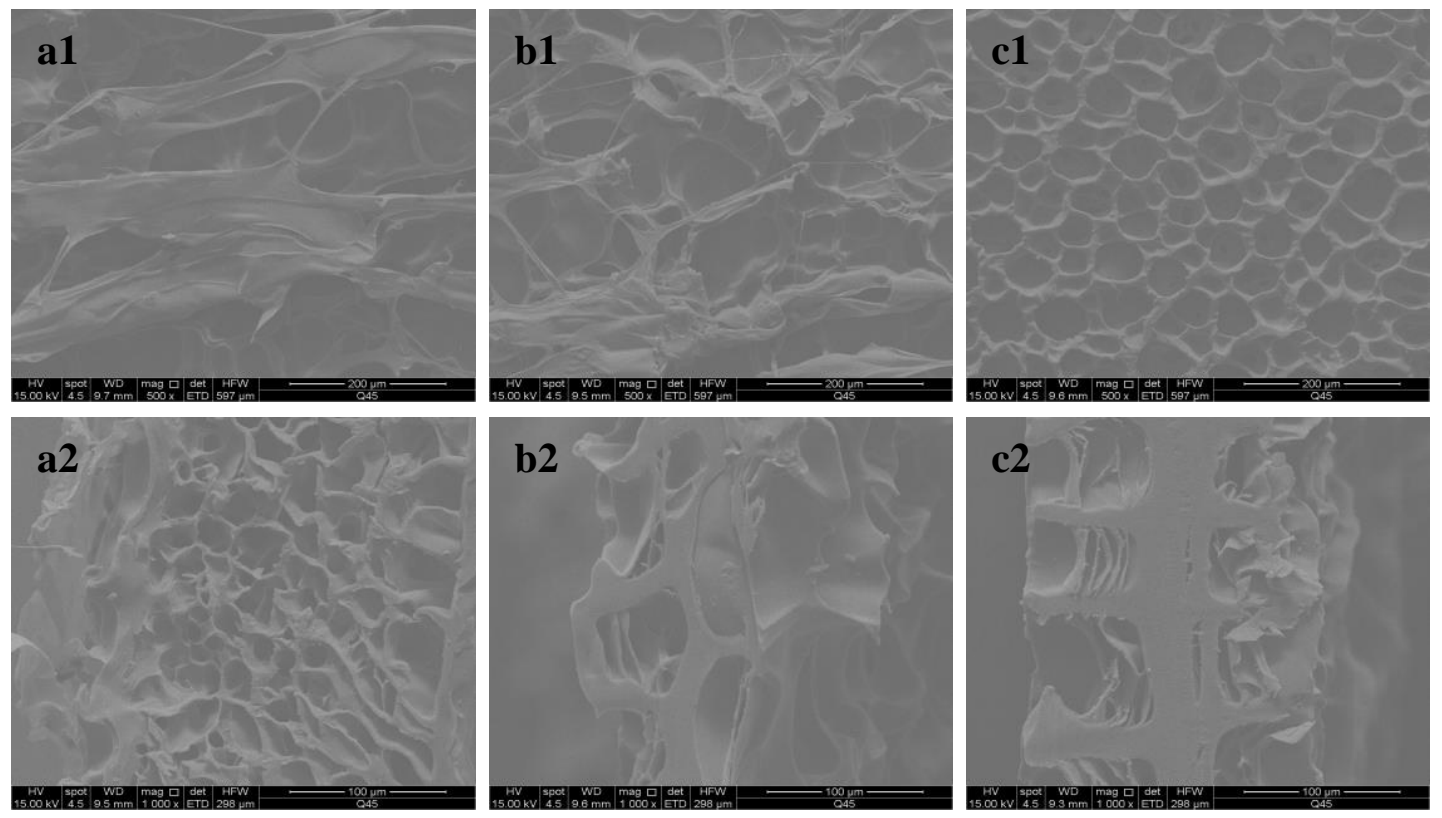

Figure S29. SEM of the surface and cross-section of different gelatin films after water swelling: a1, b1 and c1 are the surface microstructures of the blank gelatin film, gallic acid composite gelatin film and modified gallic acid crosslinked gelatin film after water swelling under $500 \times$, respectively. a2, b2 and c2 are the cross-sectional microstructures of the blank gelatin film, gallic acid composite gelatin film and modified gallic acid cross-linked gelatin film after water swelling under 1000×.

The surface of the blank gelatin film broke into a band shape after water swelling. The same destructive effect also appeared on the surface of the gallic acid composite gelatin film. On the surface of the modified gallic acid crosslinked gelatin film, a large number of holes appeared, but no cracks occurred. It can be observed in the cross-sections of different gelatin films that the blank gelatin film formed a loose and porous network structure after absorbing water, and a network structure was also clearly observed after the film structure of the gallic acid composite gelatin film was destroyed. The internal film structure of the modified gallic acid crosslinked gelatin film still existed, and there were pores on both sides. The reason could be summarized that the crosslinking effect of modified gallic acid on gelatin molecules improves the structural stability of the film after swelling in water. 


\section{References}

(1) Yin, B.; Liu, H.; Wang, Y.; Bai, J.; Liu, H.; Fu, B.. Improving volatile fatty acids production by exploiting the residual substrates in post-fermented sludge: Protease catalysis of refractory protein. Bioresour. Technol. 2016, 203, 124-131, DOI 10.1016/j.biortech.2015.12.029.

(2) Amata, O.; Marino, T.; Russo, N.; Toscano, M.. Human insulin-degrading enzyme working mechanism. J. Am. Chem. Soc. 2009, 131 (41), 14804-14811, DOI 10.1021/ja9037142.

(3) Bahmanzadeh, S.; Ruzgas, T.; Sotres, J.. Proteolytic degradation of gelatin-tannic acid multilayers. J. Colloid Interface Sci. 2018, 526, 244-252, DOI 10.1016/j.jcis.2018.04.112.

(4) de la Cruz-Gavia, A.; Perez-Alonso, C.; Barrera-Diaz, C. E.; Alvarez-Ramirez, J.; Carrillo-Navas, H.; Guadarrama-Lezama, A. Y.. Survival of Saccharomyces cerevisiae microencapsulated with complex coacervate after freezing process. Food Hydrocolloids 2018, 82, 45-52, DOI 10.1016/j.foodhyd.2018.03.045.

(5) Peng, Z.; Zhang, J.; Du, G.; Chen, J.. Keratin Waste Recycling Based on Microbial Degradation: Mechanisms and Prospects. ACS Sustainable Chem. Eng. 2019, 7 (11), 9727-9736, DOI 10.1021/acssuschemeng.9b01527.

(6) Deng, Y.; Beadham, I.; Ghavre, M.; Costa Gomes, M. F.; Gathergood, N.; Husson, P.; Legeret, B.; Quilty, B.; Sancelme, M.; Besse-Hoggan, P.. When can ionic liquids be considered readily biodegradable? Biodegradation pathways of pyridinium, pyrrolidinium and ammonium-based ionic liquids. Green Chem. 2015, 17 (3), 1479-1491, DOI 10.1039/c4gc01904k.

(7) Scaffaro, R.; Sutera, F.; Botta, L.. Biopolymeric bilayer films produced by co-extrusion film blowing. Polym. Test. 2018, 65, 35-43, DOI 10.1016/j.polymertesting.2017.11.010.

(8) Nouri, K.; Khalaji, S.; Zamani, A.; Saki, A.. Acid hydrolysis of gelatin extracted from cow skin: properties and potential for use as a source of small peptides and free amino acids for broiler chickens. Anim. Prod. Sci. 2021, 61 (4), 399-411, DOI 
10.1071/an20411.

(9) Deng, D.; Kita, Y.; Kamata, K.; Hara, M.. Low-temperature reductive amination of carbonyl compounds over $\mathrm{Ru}$ deposited on $\mathrm{Nb}_{2} \mathrm{O}_{5} \cdot \mathrm{nH}_{2} \mathrm{O}$. ACS Sustainable Chem. Eng. 2019, 7 (5), 4692-4698, DOI 10.1021/acssuschemeng.8b04324.

(10) Etxabide, A.; Vairo, C.; Santos-Vizcaino, E.; Guerrero, P.; Pedraz, J. L.; Igartua, M.; de la Caba, K.; Hernandez, R. M.. Ultra thin hydro-films based on lactose-crosslinked fish gelatin for wound healing applications. Int. J. Pharm. 2017, 530 (1-2), 455-467, DOI 10.1016/j.ijpharm.2017.08.001.

(11) Ondaral, S.; Celik, E.; Kurtulus, O. C.. The adsorption of phosphate-buffered saline to model films composed of nanofibrillated cellulose and gelatin. J. Appl. Biomater. Funct. Mater. 2019, 17 (1), 1-7, DOI 10.1177/2280800019826513.

(12) Chen, L.; Qiang, T.; Chen, X.; Ren, W.; Zhang, H. J.. Fabrication and evaluation of biodegradable multi-cross-linked mulch film based on waste gelatin. Chem. Eng. J. 2021, 419, 129639, DOI 10.1016/j.cej.2021.129639. 